Article

\title{
Spatiotemporal Patterns of Extreme Temperature across the Huai River Basin, China, during 1961-2014, and Regional Responses to Global Changes
}

\author{
Peng Sun ${ }^{1,2,3} \mathbb{( D}^{\circ}$, Qiang Zhang ${ }^{2,4,5, *}$, Rui Yao ${ }^{1,3}$, Vijay P Singh ${ }^{6}$ and Changqing Song ${ }^{2,4,5, *}$ \\ 1 College of Geography and Tourism, Anhui Normal University, Anhui 241002, China; \\ sun68peng@ahnu.edu.cn (P.S.); yaorui0730@ahnu.edu.cn (R.Y.) \\ 2 Key Laboratory of Environmental Change and Natural Disaster, Ministry of Education, \\ Beijing Normal University, Beijing 100875, China \\ 3 Anhui Key Laboratory of Natural Disaster Process and Prevention, Wuhu 241002, China \\ 4 Faculty of Geographical Science, Academy of Disaster Reduction and Emergency Management, \\ Ministry of Education/Ministry of Civil Affairs, Beijing Normal University, Beijing 100875, China \\ 5 State Key Laboratory of Earth Surface Processes and Resource Ecology, Beijing Normal University, \\ Beijing 100875, China \\ 6 Department of Biological and Agricultural Engineering and Zachry Department of Civil Engineering, \\ Texas A\&M University, College Station, TX 77843, USA; vsingh@tamu.edu \\ * Correspondence: zhangq68@bnu.edu.cn (Q.Z.); songcq@bnu.edu.cn (C.S.); \\ Tel./Fax: +86-010-5880-7086 (Q.Z.); +86-010-5880-5820 (C.S.)
}

Received: 11 March 2018; Accepted: 13 April 2018; Published: 18 April 2018

check for updates

\begin{abstract}
Global warming and its relevant effects have aroused increasing human concerns in recent decades. These anomalies are likely influencing vegetation dynamics and ecosystem stability. This paper aims to dissect extreme temperature variations in both space and time, and related regional responses to global warming in the Huai River Basin. Using the daily maximum and minimum air temperature at 153 stations across the Huai River Basin, China, covering the period of 1961-2014, trends and relations amongst extreme air temperature indices were analyzed, and regional responses of the Huai River Basin to global warming process were also investigated. The results indicated that: (1) widespread increasing trends can be observed in maximum and minimum air temperature, with the largest increasing magnitude of $0.4{ }^{\circ} \mathrm{C}$ per decade and $1.3{ }^{\circ} \mathrm{C}$ per decade, respectively. The minimum air temperature regimes have a larger increasing magnitude than the maximum air temperatures. (2) There is an increasing trend in the extreme maximum temperature indices, and the increasing rates of TN90p and TR20 are greater than those of the other extreme maximum temperature indices. However, the extreme minimum temperature indices, except for consecutive icy days (CID), show significant decreasing trends. The growing season length (GSL) would increase due to the joint action of (i) an increase in maximum temperature indices, and (ii) a decrease in minimum temperatures indices. Although increases in the GSL would be beneficial for increasing the growing time of crops, a decreased extreme minimum temperature and increased extreme maximum temperature may reduce the winter wheat yield. (3) Extreme low temperature indices show a larger changing magnitude than the extreme high temperature indices. Temporally, a larger changing magnitude can be identified for temperature indices during night-time than during daytime. Moreover, a larger changing magnitude and higher significance of trends of extreme temperature indices can be observed in the eastern Huai River Basin than in the western Huai River Basin. Particularly, we detect an even higher changing rate of extreme temperature indices in the southeastern Huai River Basin. These findings can be well explained by urban heat island effects resulting from urban aggregation across the Yangtze Delta. (4) The correlation between the extreme low temperature indices is slightly higher than that of the extreme high temperature indices. The changing trends of the most extreme temperature indices are closely related to latitude
\end{abstract}


and altitude. Trends in the main extreme temperature indices of the Huai River Basin are essentially similar to those in other regions around the world, implying consistent spatial patterns of extreme temperature indices across the globe.

Keywords: extreme temperature indices; Sen's slope; Mann-Kendall trends; warming processes; Huai River Basin

\section{Introduction}

Recent years have witnessed a warming climate that is characterized by increasing temperature at global and regional scales. Hence, extensive discussion has taken place due to the considerable impact of increased temperature on the eco-environment and society [1-4]. Previous experiments indicated that temperature extremes increase faster than the mean temperature [5,6]. Meanwhile, intensifying temperature extremes in recent decades have resulted in more and more serious fatalities and socioeconomic losses [7-10]. For instance, heat waves and extremely high temperatures can cause fatalities and losses directly by heat-related illness, or indirectly by affecting agricultural production or water availability $[4,11]$. Therefore, numerous studies have addressed the spatiotemporal features of temperature regimes [12]. These studies have observed an increasing of approximate $0.2^{\circ} \mathrm{C}$ per decade $\left(0.2{ }^{\circ} \mathrm{C} / 10 \mathrm{a}\right)$ in the global surface temperature over the past 30 years $[11,13]$. Nevertheless, temperature changes are diverse and shifting in both space and time, and there are significant variations in some regions $[12,14]$. Therefore, it is of paramount importance to investigate the changing properties of extreme temperature regimes at both regional and global scales.

As for temperature changes in China, a significant increase in temperature can be observed in the last 100 years, with an increasing magnitude of $0.9^{\circ} \mathrm{C} / 10 \mathrm{a}$, and an increasing magnitude of $0.23^{\circ} \mathrm{C} / 10 \mathrm{a}$ in the temperature over the last 50-60 years. The increasing magnitude of temperature across China over the last 100 years has been larger than the average across the globe. In addition, in eastern China, the increasing magnitude of temperature during 1909-2010 reached $1.52{ }^{\circ} \mathrm{C} / 100 \mathrm{a}$ [15]. Increasing temperature triggers an instability of atmospheric conditions, and hence an enhancement of extreme weather events. Thus, investigations of extreme temperature have been drawing increasing humans concern from the international academic community $[2,9,11]$. As stated previously, numerous research studies have been conducted on the changing properties of extreme temperature regimes across both space and time. Christidis et al. (2005) and Stott (2016) indicated that the maximum and minimum temperature have been increasing at the global scale, with an elevating frequency and intensity of weather extremes [16,17]. Dashkhuu et al. (2015) analyzed various indices to investigate recent changes in the annual frequencies of extreme temperature events in Mongolia, showing an apparent increase in summer days, as well as an appreciable decrease in frost days [18]. Ruml et al. (2017) analyzed spatiotemporal changes of temperature extremes in Serbia based on 18 Expert Team on Climate Change Detection and Indices (ETCCDI) indices using daily minimum and maximum temperature observations from 26 meteorological stations over the period 1961-2010. They found that that hot indices exhibited a general cooling tendency until 1980, and a warming tendency afterwards, with the most pronounced trends in the number of summer and tropical days. Meanwhile, cold indices displayed a mostly warming tendency over the entire period, with the most remarkable increase in the lowest annual maximum temperature and the number of ice days [19]. Lin-Ye et al. (2018) proposed a non-stationary multivariate statistical model considering significant wave heights and peak wave periods at the peak of wave storms, as well as total storm energy and storm duration. They found that multivariate models can be a suitable alternative for assessing the correlation of several indices at the same time [20]. As for temperature changes in China, Zhang et al. (2017) indicated that changes in temperature extremes considerably exceeded variations in the respective climatological 
means during the past five decades, with a greater amplitude of increases in cold extremes than in warm extremes [21]. Besides, urban heat island effects have also been quantified across China [22,23].

China is the largest agricultural country with the largest population in the world [24-26]. Eastern China accounts for more than $70 \%$ of the total population of the country [27]. What's more, the study region considered in this study, the Huai River Basin, is located in eastern China (Figure 1). The Huai River Basin is densely populated, and has great socioeconomic potential. The basin provides $10 \%$ of the total crop land of China and $20 \%$ of its total agricultural products, feeding $20.4 \%$ of the total countryside population $[28,29]$. Hence, agricultural development in the Huai River Basin is critical for the food security of China. Nevertheless, the Huai River Basin lies in the transitional zone between semi-arid and semi-humid climates, being dominated by frequent droughts and floods. Since the beginning of the $21^{\text {st }}$ century, the annual average drought-affected crop area reached $2.698 \mathrm{hm}^{2} \times 10^{6} \mathrm{hm}^{2}$ and the drought-destroyed cropland area has reached $1.408 \mathrm{hm}^{2} \times 10^{6} \mathrm{hm}^{2}$, accounting for $21 \%$ and $11 \%$ of the total cropland of the basin, respectively [25]. However, temperature changes have remarkable impacts on droughts [30]. Besides, variations of temperature have affected the lengths of growing season in both space and time, which have substantial implications for agricultural activities [31]. However, few reports were found pertaining to investigations of extreme temperature regimes across the Huai River Basin [32-34].

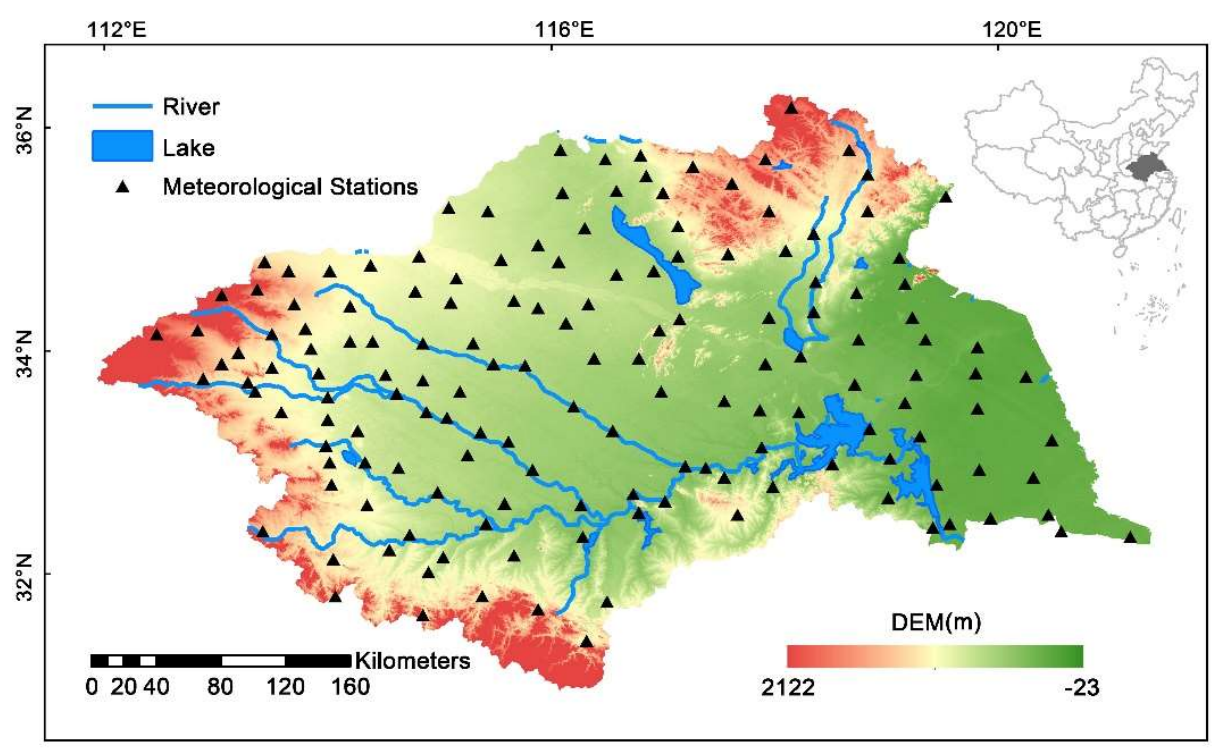

Figure 1. Locations of the study region and the meteorological stations across the Huai River Basin.

The objective of this study is to dissect the changes in extreme temperatures with a complete picture of temperature indices, and to quantify the correlations between growing season length and temperature changes. Meanwhile, according to global comparisons of temperature variations, we have also shown regional temperature responses and variations to global temperature changes. In this case, based on daily maximum and minimum air temperature from 153 meteorological stations covering the period of 1961-2014, spatiotemporal patterns of extreme temperature regimes were thoroughly analyzed using 26 extreme temperature indices. In addition, regional responses of temperature changes in the Huai River Basin were analyzed by comparing changes of extreme temperature within the Huai River Basin with those in other regions of the globe. This study will be of paramount significance in shedding new light on extreme temperature changes in both space and time, and their regional responses to global warming climate.

This paper is organized as follows. Section 2 describes the study region and data sources. Extreme indices and statistical methods are presented in Section 3. The temporal and spatial characteristics of extreme temperature changes in the study area are analyzed in Section 4 . Section 5 presents the regional 
responses of warming processes in the Huai River Basin to global changes, and conclusions are given in Section 6.

\section{Data}

In situ observed precipitation data from 153 meteorological stations across the Huai River Basin were collected from the China Meteorological Information Center [35]. Locations of the meteorological stations were shown in Figure 1. The missing values of precipitation data for 1-2 days were filled by the average precipitation of the neighboring days. Consecutive days with missing data were interpolated by the long-term average of other years. For the objectives of this study, this gap-fill method did not significantly affect the final results. A similar method had been used by Zhang et al. to fill daily missing precipitation values [36].

\section{Methods}

\subsection{Extreme Temperature Indices and Sen's Trends}

In this study, 26 extreme temperature indices were defined (Table 1) [19]. A description of the 26 indices based on the daily maximum temperature and daily minimum temperature are presented, as defined by an Expert Team on Climate Change Detection and Indices (ETCCDI) experts. These indices have been used in several studies regarding changes in temperature extremes (http:/ / etccdi. pacificclimate.org/list_27_indices.shtml), which are calculated by the RclimDex software package (http:/ / etccdi.pacificclimate.org/software.shtml). The indices can be divided into four groups: (1) extreme indices, (2) extreme maximum temperature indices, (3) extreme minimum temperature indices, and (4) other indices.

Table 1. Definitions of extreme temperature indices.

\begin{tabular}{|c|c|c|c|c|}
\hline Categories & Abbreviation & Indices & Definitions & Unit \\
\hline \multirow{3}{*}{ Extreme indices } & $\mathrm{TXx}$ & $\begin{array}{l}\text { The highest temperature of } \\
\text { the maximum temperature } \\
\text { series }\end{array}$ & $\begin{array}{l}\text { The highest temperature of the daily and } \\
\text { monthly maximum temperature }\end{array}$ & ${ }^{\circ} \mathrm{C}$ \\
\hline & TXn & $\begin{array}{l}\text { The lowest temperature of } \\
\text { the maximum temperature } \\
\text { series }\end{array}$ & $\begin{array}{l}\text { The lowest temperature of the daily and } \\
\text { monthly maximum temperature }\end{array}$ & ${ }^{\circ} \mathrm{C}$ \\
\hline & $\mathrm{TNn}$ & $\begin{array}{l}\text { The lowest temperature of } \\
\text { the minimum temperature } \\
\text { series }\end{array}$ & $\begin{array}{l}\text { The lowest temperature of the daily and } \\
\text { monthly minimum temperature }\end{array}$ & ${ }^{\circ} \mathrm{C}$ \\
\hline \multirow{6}{*}{$\begin{array}{l}\text { Extreme maximum } \\
\text { temperature indices }\end{array}$} & TX90p & Number of warm days & $\begin{array}{l}\text { Number of days with annual maximum } \\
\text { temperature }>90 \text { th percentile }\end{array}$ & $\mathrm{d}$ \\
\hline & SU25 & Number of summer days & $\begin{array}{l}\text { Days with annual maximum temperature } \\
>25{ }^{\circ} \mathrm{C}\end{array}$ & $\mathrm{d}$ \\
\hline & SU35 & Number of heat days & $\begin{array}{l}\text { Days with annual maximum temperature } \\
>35^{\circ} \mathrm{C}\end{array}$ & $\mathrm{d}$ \\
\hline & TR20 & $\begin{array}{l}\text { Number of days with heat } \\
\text { nights }\end{array}$ & $\begin{array}{l}\text { Days with annual minimum temperature } \\
>20^{\circ} \mathrm{C}\end{array}$ & $\mathrm{d}$ \\
\hline & WSDI & Consecutive warm days & $\begin{array}{l}\text { At least six consecutive days with daily } \\
\text { maximum temperatures }>90 \text { th percentile }\end{array}$ & $\mathrm{d}$ \\
\hline & HWDI & Heat wave days & $\begin{array}{l}\text { At least six consecutive days with daily } \\
\text { maximum temperatures } 5^{\circ} \mathrm{C} \text { higher than } \\
\text { average maximum temperature }\end{array}$ & $\mathrm{d}$ \\
\hline
\end{tabular}


Table 1. Cont

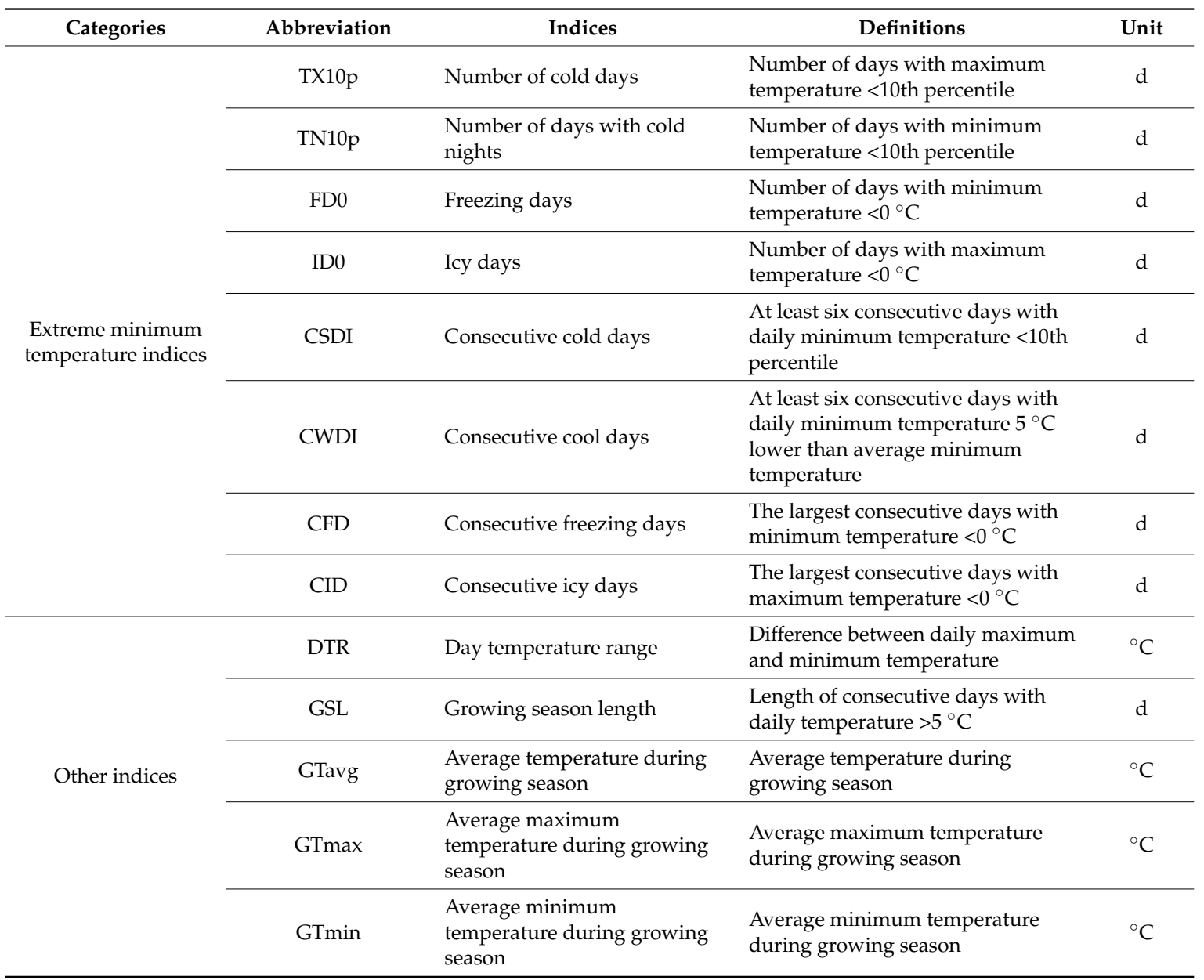

An estimation of the magnitude of trends was done using Sen's slope [37], which is a non-parametric procedure for estimating the slope of trend in the sample of $N$ pairs of data:

$$
Q_{i}=\frac{x_{j}-x_{k}}{j-k} \text { for } i=1,2, \ldots N,
$$

where $x_{j}$ and $x_{k}$ are the data values at times $j$ and $k(j>k)$, respectively, and $Q_{i}$ is Sen's slope.

If there is only one datum in each time interval, then $N=n(n-1) / 2$, where $n$ is the number of time intervals. If there are multiple observations in one or more time periods, then $N<n(n-1) / 2$, where $\mathrm{n}$ is the total number of observations [38]. The $N$ values of $Q_{i}$ are ranked from smallest to largest, and the median of slope or Sen's slope estimator is obtained by [38]:

$$
Q_{\text {med }}= \begin{cases}Q_{\left[\frac{N+1}{2}\right]} & \text { if } N \text { is odd } \\ \frac{Q_{N}+Q_{\frac{N+2}{2}}}{2} & \text { if } N \text { is even }\end{cases}
$$

The $Q_{\text {med }}$ denotes the magnitude of trends in a hydrometeorological time series [39]. $Q_{\text {med }}>0$ indicates increasing trends, and vice versa.

\subsection{Mann-Kendall (MK) Trend Test Method}

In this study, abrupt changes were tested using the algorithm by Gerstengarbe and Werner [40]. We assume a sample, $x_{1}, x_{2}, \ldots, x_{n}$, of the random variable, $X$, based on the rank series $r$ of 
the progressive and retrograde rows of this sample. First, a Mann-Kendall (MK) test statistic, $d_{k}$, is calculated:

$$
d_{k}=\sum_{i=1}^{k} r_{i}(2 \leq k \leq n)
$$

and:

$$
r_{i}=\left\{\begin{array}{ll}
+1 & \text { if } x_{i}>x_{j} \\
0 & \text { otherwise }
\end{array} \quad(j=1,2, \ldots, i)\right.
$$

The statistic $d_{k}$ is distributed as a normal distribution with the expected value of $E\left(d_{k}\right)$, and the variance $\operatorname{Var}\left(d_{k}\right)$ as follows:

$$
\begin{gathered}
E\left[d_{k}\right]=\frac{n(n-1)}{4} \\
\operatorname{Var}\left[d_{k}\right]=\frac{n(n-1)(2 n+5)}{72}
\end{gathered}
$$

The definition of the statistic index $Z_{k}$ is calculated as:

$$
Z_{k}=\frac{d_{k}-E\left[d_{k}\right]}{\sqrt{\operatorname{var}\left[d_{k}\right]}}(k=1,2,3, \ldots, n)
$$

$Z_{k}$ follows the standard normal distribution. In a two-sided test for trend, the null hypothesis is rejected at the significance level of $\alpha$ if $\left|Z_{k}\right|>Z_{(1-\alpha / 2)}$, where $Z_{(1-\alpha / 2)}$ is the critical value of the standard normal distribution with a probability exceeding $\alpha / 2$. A positive $Z_{k}$ value denotes a positive trend, and a negative $Z_{k}$ value denotes a negative trend. In this paper, the significant level of $\alpha=5 \%$ is used. In contrast to the traditional MK test, which calculates above statistic variables only once for the whole sample, the corresponding rank series for the so-called retrograde rows are similarly obtained for the retrograde sample $\left(x_{n}, x_{n-1}, \ldots, x_{1}\right)$. Following the same procedure as shown in Equations (1)-(5), the statistic variables, $d_{k}, E\left(d_{k}\right), \operatorname{Var}\left(d_{k}\right)$, and $Z_{k}$ will be calculated for the retrograde sample. The $Z$ values calculated with the progressive and retrograde series are named $U F$ and $U B$ in this paper, respectively. The intersection point of the two lines, $U F$ and $U B(k=1,2, \ldots, n)$, gives the point in time of the abrupt changes within the time series. The null hypothesis (the sample is not affected by a trend) must be rejected if the intersection point is significant at $5 \%$ significance level (i.e., outside the 95\% confidence interval) [41]. Besides, spatial interpolation in this study was done by the Kriging method, and correlations between extreme temperature indices were quantified using Pearson correlation coefficients. No further detailed information of these methods is provided here, as these methods have been widely used in the study of hydrometeorology.

\section{Results and Discussion}

\subsection{Trends in Extreme Temperature Indices}

Table 1 enumerates the extreme temperature indices considered in this study, and Table 2 shows the trends in 26 extreme temperature indices during 1961-2014 at 153 stations across the Huai River Basin. For extended descriptions regarding the parameters for the following acronyms, please refer to Table 1. The lowest temperature of the maximum temperature series ( $\mathrm{TXn}$ ), the highest temperature of the minimum temperature series $(\mathrm{TNx})$, and the lowest temperature of the minimum temperature series (TNn) had positive trends at most stations across the Huai River Basin. In particular, TNx and TNn had significant increasing trends at 97 out of 122 stations. Besides, the number of warm days (TN90p), the number of summer days (SU25), the number of days with heat nights (TR20), and the number of heat wave days (HWDI) had increasing trends, and the number of days with warm nights (TN90p and TR20) had significant increasing trends at $98.04 \%$ and $83.01 \%$ of the total stations, respectively. Therefore, low temperature components were subject to increasing trends. Meanwhile, the number of cold days (TX10p), the number of days with cold nights (TN10p), the number of freezing 
days (FD0), the number of consecutive cold days (CSDI), the number of consecutive cool days (CWDI), and the number of consecutive freezing days (CFD) all had decreasing trends. Wherein, FD0, TN10p, CSDI, CWDI, and CFD had significant increasing trends at $96.73 \%, 93.46,91.50 \%, 90.20 \%$ and $84.31 \%$ of the total meteorological stations, respectively. These figures implied a larger increasing magnitude and significant warming processes in the Huai River Basin, as reflected by the cold temperature components. Minimum temperature trends increased more than maximum temperature trends. Karl et al. (1993) analyzed monthly mean maximum and minimum temperatures for over 50\% (10\%) of the Northern (Southern) Hemisphere landmass, indicating that the increment in the minimum temperature during 1951-1990 was $0.84{ }^{\circ} \mathrm{C}\left(0.56^{\circ} \mathrm{C}\right)$, compared to a $0.28^{\circ} \mathrm{C}\left(0.33^{\circ} \mathrm{C}\right)$ rise in maximum temperatures [42]. Zhang et al. (2008) analyzed the statistical properties of temperature extremes in the Yellow River Basin. They observed significant warming trends in the upper Yellow River Basin. Besides, they also indicated that the warming tendency of the Yellow River Basin was mainly reflected by its significantly increasing minimum temperature [43].

Table 2. Trends in extreme temperature indices during 1961-2014 across the Huai River basin.

\begin{tabular}{|c|c|c|c|c|c|c|c|c|c|c|c|c|c|}
\hline TI & Percentage & NSU & NU & NSD & ND & NT & TI & Percentage & NSU & NU & NSD & ND & NT \\
\hline $\mathrm{TXx}$ & $9.80 \%$ & 14 & 69 & 1 & 66 & 18 & TX10p & $43.14 \%$ & 0 & 1 & 66 & 152 & 0 \\
\hline TXn & $29.41 \%$ & 45 & 153 & 0 & 0 & 0 & TN10p & $93.46 \%$ & 0 & 0 & 143 & 153 & 0 \\
\hline $\mathrm{TNx}$ & $63.40 \%$ & 97 & 142 & 0 & 1 & 10 & FD0 & $96.73 \%$ & 0 & 0 & 148 & 152 & 1 \\
\hline TNn & $79.74 \%$ & 122 & 151 & 0 & 2 & 0 & ID0 & $30.07 \%$ & 0 & 0 & 46 & 89 & 65 \\
\hline TX90p & $20.26 \%$ & 31 & 101 & 0 & 51 & 1 & CSDI & $91.50 \%$ & 0 & 0 & 140 & 152 & 1 \\
\hline TN90p & $98.04 \%$ & 150 & 153 & 0 & 0 & 0 & CWDI & $90.20 \%$ & 0 & 0 & 138 & 152 & 1 \\
\hline SU25 & $44.44 \%$ & 68 & 153 & 0 & 0 & 2 & CFD & $84.31 \%$ & 0 & 0 & 129 & 151 & 2 \\
\hline SU35 & $11.76 \%$ & 13 & 39 & 5 & 67 & 47 & CID & $3.92 \%$ & 0 & 0 & 6 & 10 & 143 \\
\hline TR20 & $83.01 \%$ & 127 & 147 & 0 & 2 & 4 & DTR & $81.70 \%$ & 2 & 8 & 123 & 144 & 1 \\
\hline WSDI & $3.92 \%$ & 2 & 14 & 4 & 66 & 73 & GSL & $83.01 \%$ & 127 & 153 & 0 & 0 & 0 \\
\hline HWDI & $9.15 \%$ & 14 & 139 & 0 & 0 & 14 & GTavg & $81.70 \%$ & 0 & 0 & 125 & 153 & 0 \\
\hline CSU25 & $3.92 \%$ & 3 & 34 & 3 & 101 & 18 & Gtmax & $81.70 \%$ & 0 & 0 & 125 & 153 & 0 \\
\hline CSU35 & $7.84 \%$ & 8 & 14 & 4 & 23 & 116 & Gtmin & $83.66 \%$ & 0 & 0 & 128 & 153 & 0 \\
\hline
\end{tabular}

Note: TI: extreme temperature indices; Percentage: percentage of stations with significant trends in extreme temperature indices; NSU: number of stations with significant increasing trends in extreme temperature indices; NU: number of stations with increasing tendencies in extreme temperature indices; NSD: number of stations with significant decreasing trends in extreme temperature indices; ND: number of stations with decreasing tendencies in extreme temperature indices; NT: no trends can be detected in extreme temperature indices.

A larger increasing magnitude of minimum temperature than the maximum temperature can definitely reduce the DTR, i.e., the difference between the daily maximum and daily minimum temperature. In the Huai River Basin, a decreasing DTR can be observed at 144 stations, while the DTR at 123 stations showed significant decreasing trends. Moreover, more than $80 \%$ of the stations were characterized by significant trends regarding the growing season length (GSL), the average temperature during the growing season (GTave), the maximum temperature during the growing season (GTmax), and the minimum temperature during the growing season (GTmin). Wherein GSL showed increasing trends, and decreasing trends could be found in the GTavg, GTmax, and GTmin. The above-mentioned results implied a remarkable increase in the minimum temperature and a decrease of cold days, and hence a lengthening growing season, which may imply shifting agricultural activities in terms of plant timing and types of crops. In addition, the consecutive heat days (CSU35) and consecutive icy days (CID) at most of the stations across the Huai River Basin did not significantly change, indicating moderate climate conditions due to transitional regions of the Huai River Basin between northern and southern China. In space, increasing extreme temperature indices could be observed across the majority of the regions for the Huai River Basin (Figure 2). However, more significant changes in the highest temperature of the maximum temperature series (TXX) and TXn could be detected in the eastern Huai River Basin than in the western Huai River Basin. Meanwhile, significant changes in the TXx could be observed in the southeastern Huai River Basin (Figure 2a). TXn displayed significant increasing trends in the eastern Huai River Basin (Figure 2b). Parts of stations in the northwestern Huai 
River Basin were dominated by decreasing TXx, and significant increasing trends could be observed for TNx and TNn (Figure 2c,d). Meanwhile, a larger changing magnitude of TNn was detected when compared with that of TNx. Furthermore, more significant increasing trends could be found for TNx, $\mathrm{TNn}, \mathrm{TXx}$, and TXn, implying a remarkable decrease in low temperature regimes with decreasing temperature ranges. The regions with significant trends were those that were dominated by a larger standard deviation. Meanwhile, the smallest standard deviation could be found in the southeastern Huai River Basin (Figure 3).

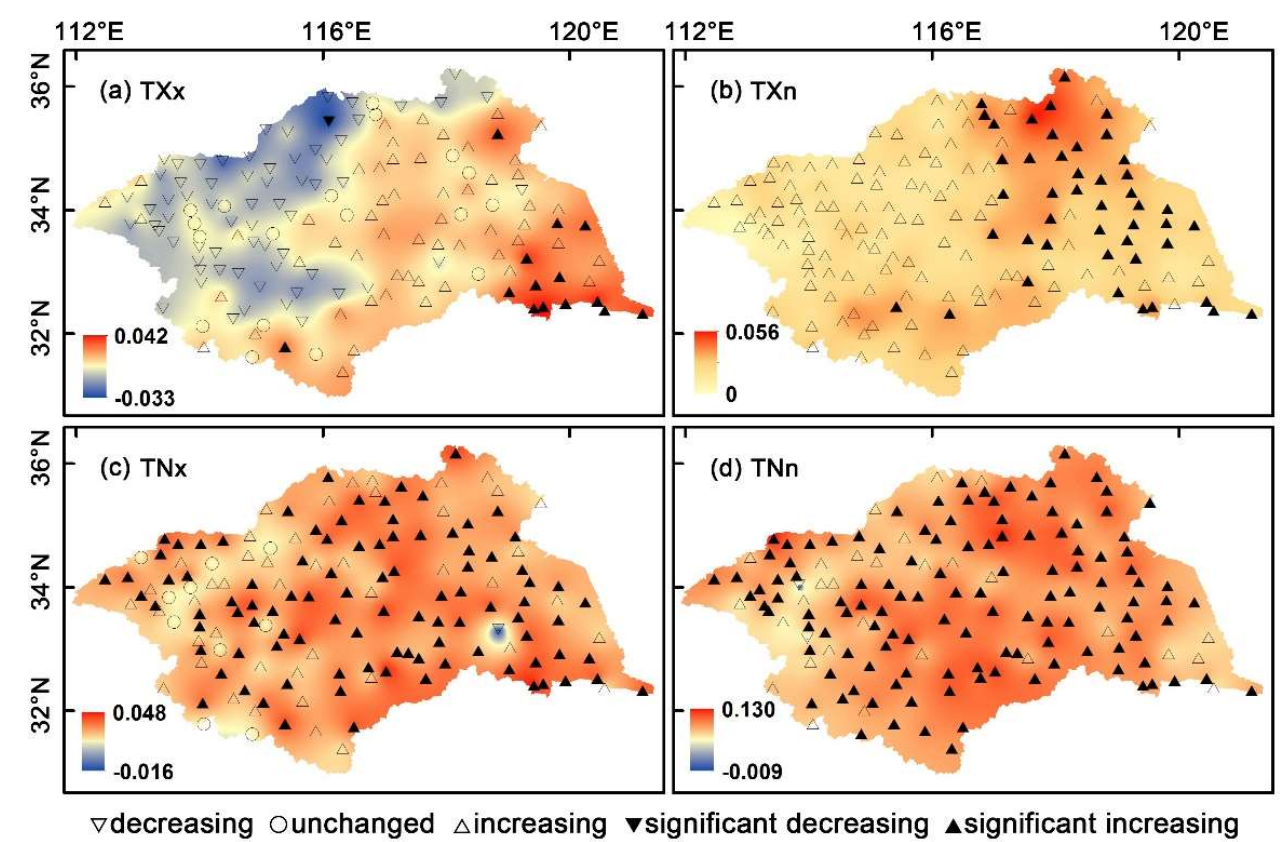

Figure 2. Spatiotemporal patterns of trends in extreme indices across the Huai River basin. Definitions of TXx, TXn, TNx, and TNn can be found in Table 1.
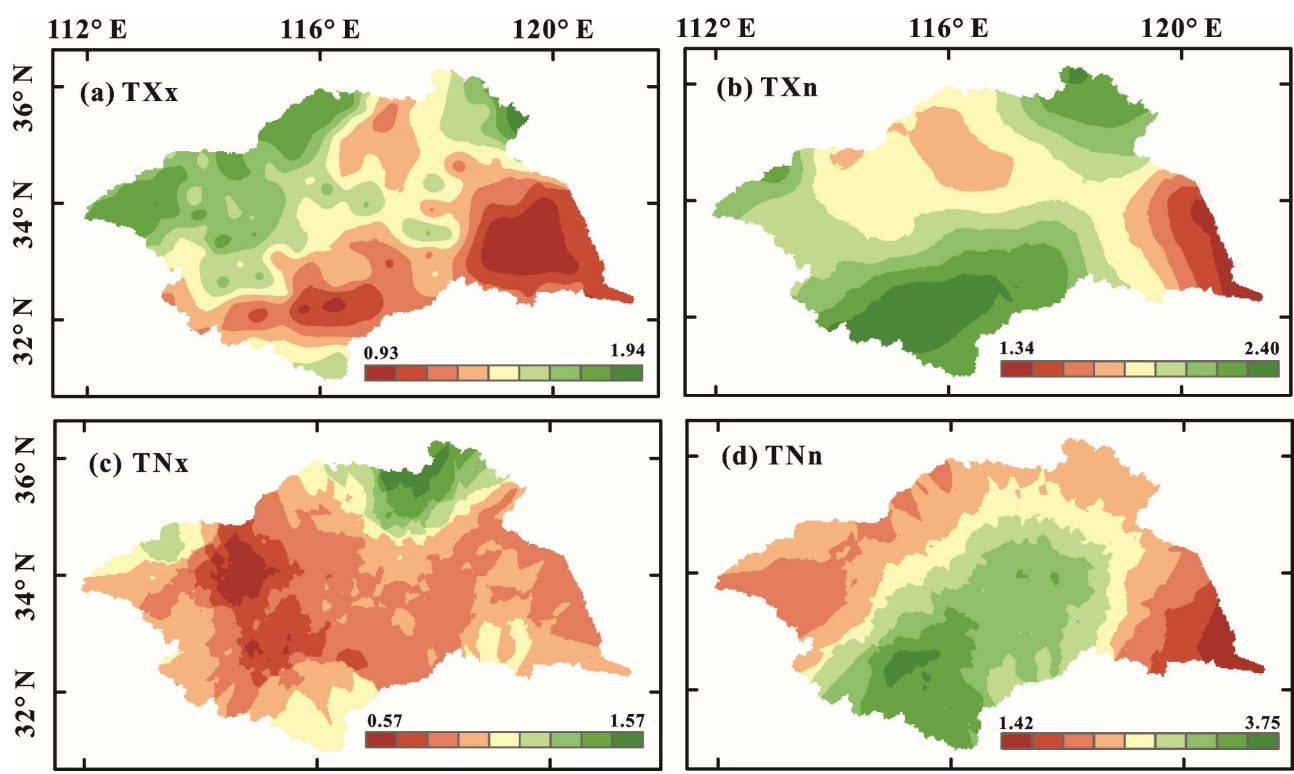

Figure 3. Spatiotemporal patterns of the standard deviation in extreme indices across the Huai River basin. Definitions of TXx, TXn, TNx, and TNn can be found in Table 1. 


\subsection{Trends of Extreme Maximum Temperature Indices}

Increasing/decreasing trends of TX90p could be detected in the eastern/western Huai River Basin (Figure 4), wherein TX90p showed a significant trend in the southeastern Huai River Basin. Meanwhile, a significant increasing TX90p could also be observed in parts of southern Huai River Basin (Figure 4a). Furthermore, in the majority of the regions of the Huai River Basin, increasing trends could be detected in TN90p, SU25, TR20, and the number of heat wave days (HWDI) with different increasing magnitudes. In particular, TN90p showed the most significant increasing trend (Figure 4b). Meanwhile, TR20 was subject to the largest increasing magnitude of $7.1 \mathrm{~d} / 10$ years (Figure 4e). However, different changing properties could be found for SU25 and the number of consecutive summer days (CSU25), respectively. Comparatively, SU25 showed an increasing trend in most of the regions of the Huai River Basin (Figure 4c), while CSU25 showed a decreasing trend in most of the regions of the Huai River Basin (Figure 4h). Even when observing warming tendencies, it was difficult to identify consecutive warm periods, indicating complicated and intermittent warm and cold climate types across the Huai River Basin. No significant trends could be detected for the number of heat days (SU35), consecutive warm days (WSDI), or CSU35 at 47, 73, and 116 stations, respectively. Meanwhile, these temperature indices were mostly increasing in the southeastern Huai River Basin, but were mostly decreasing in the northwestern Huai River Basin (Figure $4 \mathrm{~d}, \mathrm{f}, \mathrm{i}$ ). These changing properties were related closely to the latitudes and topographical features of the study region. With the exception of CSU25, other extreme maximum temperature indices also showed significant increasing trends in the majority of regions in the southeastern Huai River Basin, which should be attributed to the booming socioeconomic development of the southeastern Huai River Basin. Besides, fast urbanization and related urban heat island effects also have demonstrated remarkable contributions to increases in extreme maximum temperature indices components; these results are in line with those by Shi et al. (2009). No spatial persistency could be found for extreme maximum temperature indices and standard deviations. The dispersion degree of TX90p, WSDI, and CSU35 in the southeastern Huai River Basin was larger than that of the other regions of the study region (Figure 5a,f,i), implying a larger variability of extreme temperature indices in the southeastern Huai River Basin. Adverse changing patterns could be found for SU35 and CSU25 across space (Figure 5d,h).

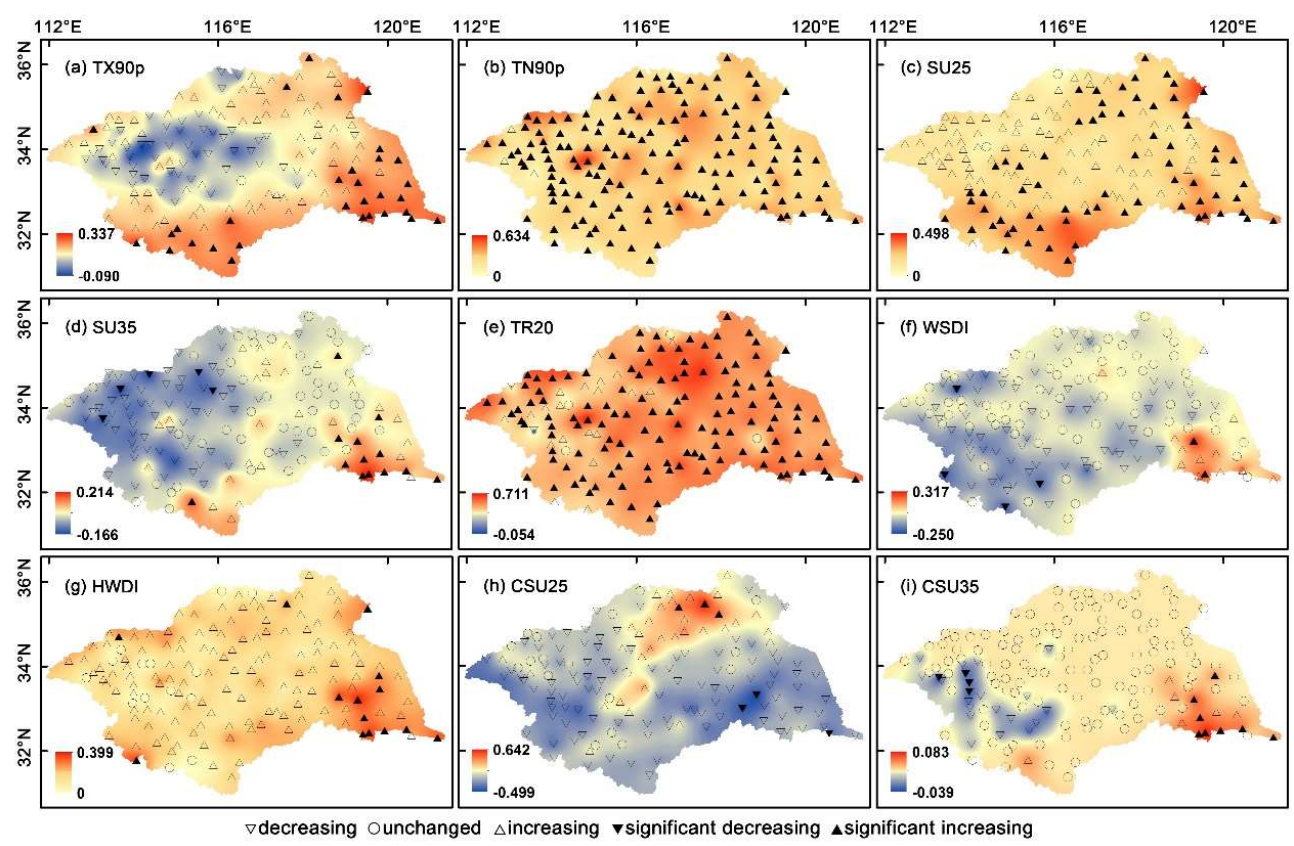

Figure 4. Spatiotemporal patterns of trends in extreme maximum temperature indices during 1960-2014 across the Huai River Basin. 

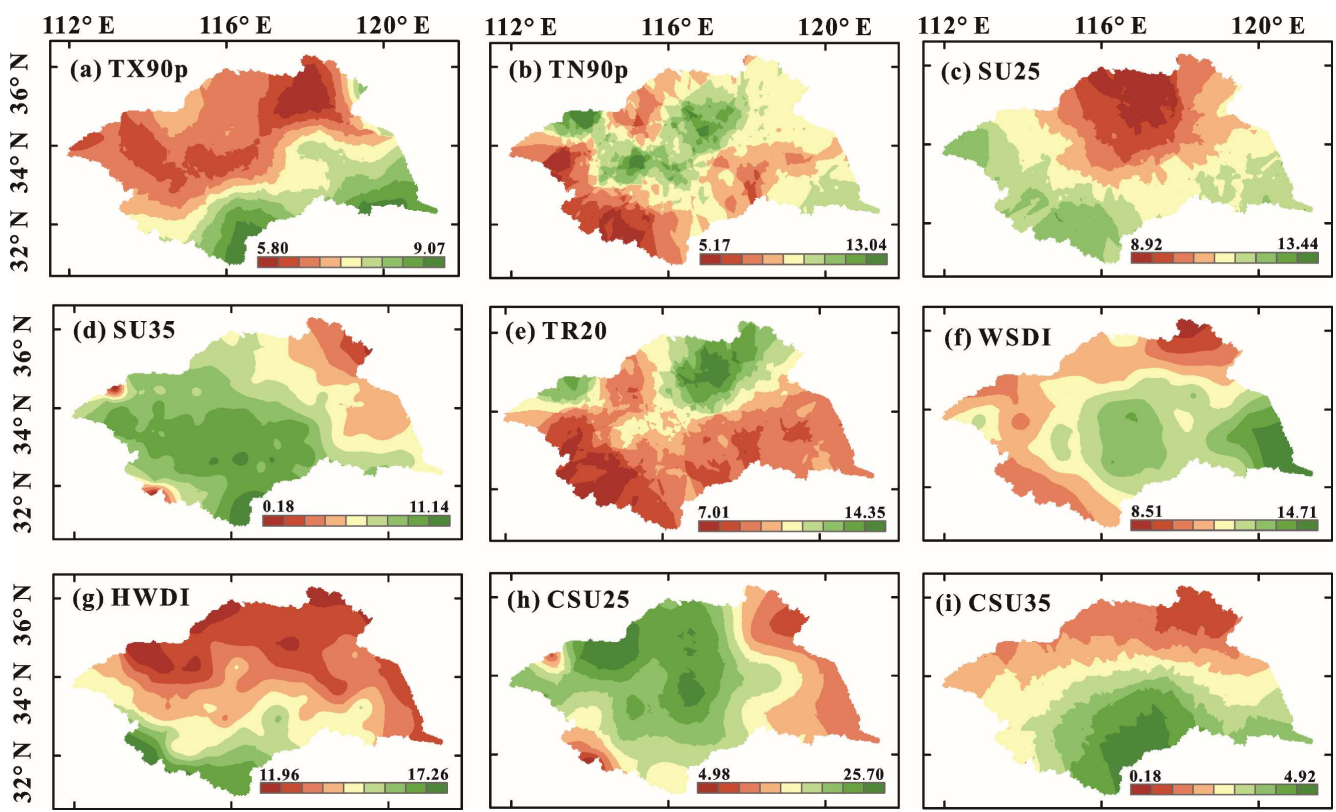

Figure 5. Spatiotemporal patterns of standard deviation in extreme maximum temperature indices during 1960-2014 across the Huai River Basin.

\subsection{Trends of Extreme Minimum Temperature Indices}

In contrast to the generally increasing tendency/trends in extreme maximum temperature indices components, the extreme minimum temperature indices components across the Huai River Basin were generally decreasing (Figure 6), and specifically, the minimum temperature and cold days were increasing. TN10p, FD0, CSDI, CWDI, and CFD generally showed decreasing trends, and significant decreasing trends in the above-mentioned minimum temperature indices were detected at $84 \%$ of the total meteorological stations. Meanwhile, the decreasing magnitudes of FD0, CSDI, and CWDI were larger than those of the other extreme minimum temperature indices (Figure $6 \mathrm{c}, \mathrm{e}, \mathrm{f}$ ), with decreasing magnitudes of 10.0 days, 9.2 days, and 7.1 days per decade, respectively. Forty-six of the stations were dominated by significant decreasing trends of icy days (ID0), and these stations were located mainly in the eastern Huai River Basin (Figure 6d). Correspondingly, CID showed no evident changes at most of the meteorological stations; the stations that were distributed sporadically across the eastern Huai River Basin were dominated by significant decreasing CID, with smaller decreasing magnitudes (Figure 6h). The standard deviation in the extreme minimum temperature was far smaller than that of the extreme maximum temperature indices. With the exception of CFD, the dispersion degree of the other extreme minimum temperatures in the eastern Huai River Basin was far more higher than that of the western Huai River Basin. (Figure 7g).

In general, a larger decreasing magnitude of minimum temperature components was observed in the northern Huai River Basin than in the southern Huai River Basin, i.e., the warming tendency was more remarkable in the northern Huai River Basin than in the southern Huai River Basin. Hence, there was a lower occurrence frequency of extreme cold temperature events, which was particularly true for CFD. When compared to the changing magnitude of the maximum temperature components, a smaller changing magnitude of the minimum temperature components was observed. These findings are in good agreement with those by Zhang et al. (2011a), which indicated that warming processes across China are dominated by a significant increasing minimum air temperature, as well as a relatively smaller increasing magnitude of maximum air temperature [12]. However, these changing properties are not homogenous across the entire Huai River Basin. In general, a larger warming magnitude can be observed in the eastern Huai River Basin when compared to the warming magnitude in the western Huai River Basin. These results can be attributed to the different intensities of the human activities 
in different parts of the Huai River Basin. Meanwhile, generally similar decreasing tendencies in the minimum air temperature could be observed across almost the entire Huai River Basin. Therefore, at this point, the warming processes were similar to those across the globe. The study found that the number of spikes and kernels per spike of winter wheat respectively decreased, as $20.5 \mathrm{spikes} / \mathrm{m}^{2}$ and 2.4 kernels/spike, respectively, when the minimum temperature increased by $1{ }^{\circ} \mathrm{C}$ in winter [44]. A decreasing extreme minimum temperature and increasing extreme high temperature may reduce the winter wheat yield.

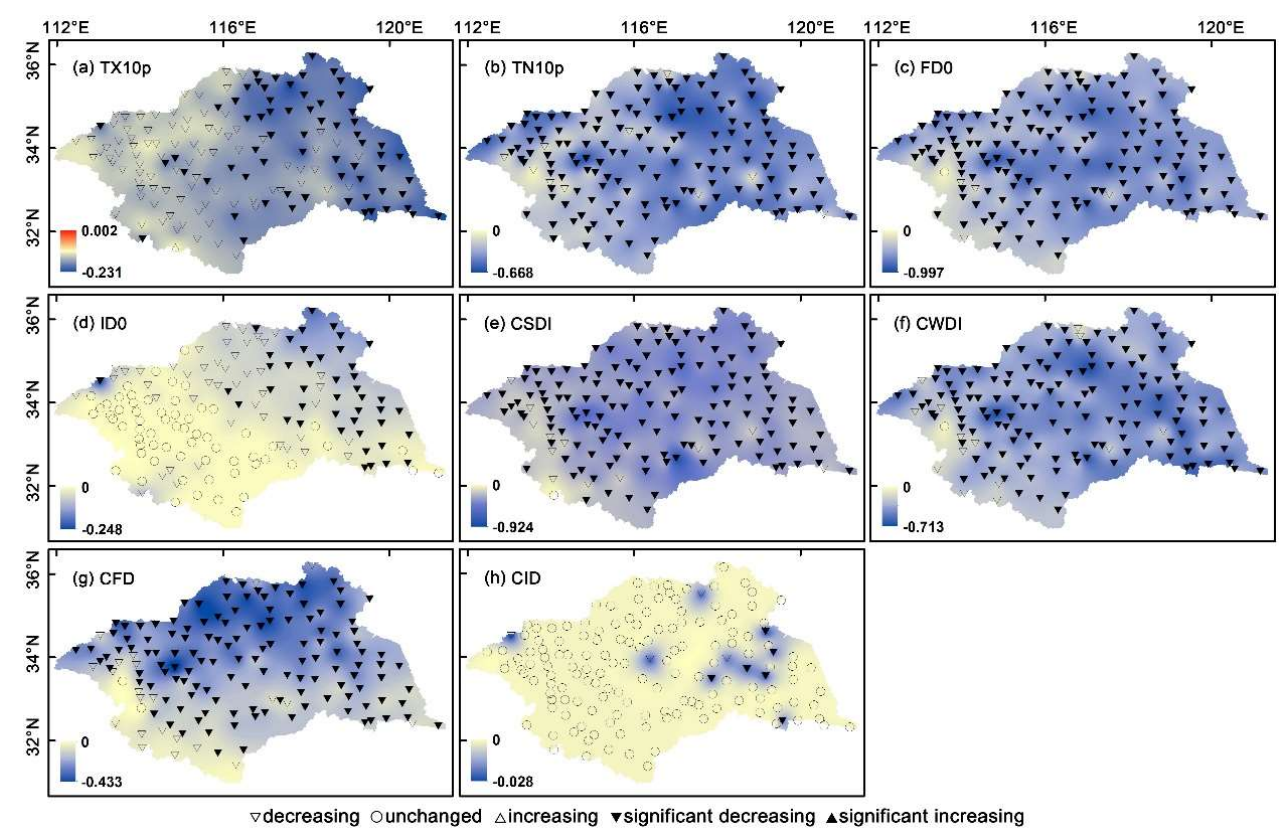

Figure 6. Spatiotemporal patterns of trends in extreme minimum temperature indices during 1961-2014 across the Huai River Basin.
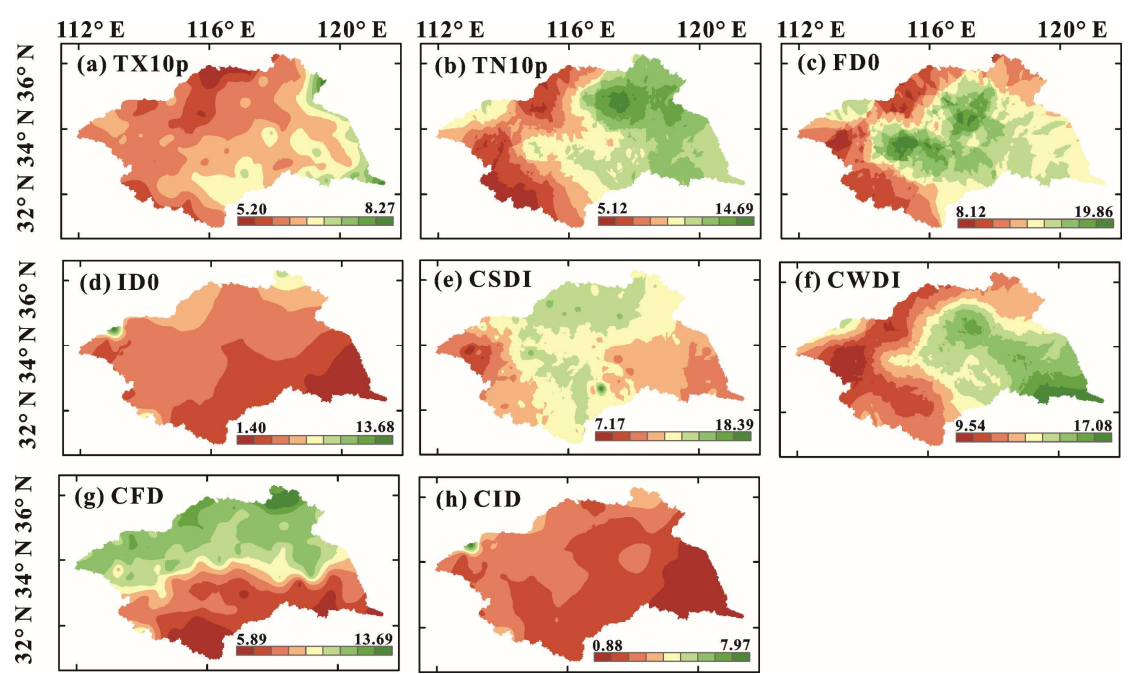

Figure 7. Spatiotemporal patterns of standard deviation in extreme minimum temperature indices during 1961-2014 across the Huai River Basin.

\subsection{Trends in Other Indices}

Stations that were dominated by a significant decreasing DTR could be observed at $80.4 \%$ of the total meteorological stations with smaller changing magnitudes. With the exception of 
the Dabieshan Mountains, which did not show a significant decreasing trend in the DTR, significant decreasing trends of DTR were detected in most of the regions of the Huai River Basin. Meanwhile, the DTR in the southeastern corner of the Huai River Basin showed significant increasing trends, and these results were adverse to those in the other regions of the Huai River Basin. It can be seen from Figure 2c that the TNx in the southeastern corner of the Huai River Basin is decreasing, while increasing trends can be detected in TXx and TXn (Figure 2a,b). Therefore, an increasing maximum air temperature, but decreasing minimum air temperature, triggers an increasing DTR.

The GSL is subject to a larger changing magnitude. The highest increasing rate of GSL was $7.6 \mathrm{~d} / 10 \mathrm{a}$, and a significant increasing or lengthening GSL could be identified at $83.01 \%$ of the total meteorological stations (Figure 8b); these stations were found mainly in the central and eastern Huai River Basin. However, fewer stations at the western edge of the Huai River Basin were dominated by a significant lengthening GSL (Figure 8b). In addition, GTavg, GTmax, and GTmin were subject to similar spatial patterns of GSL changes (Figure 8c-e). Thus, the lengthening of the GSL can cause the starting and ending timing of the GSL to extend to two ends of the year; hence, it will definitely involve more cold days, and can cause a relatively lower average temperature during the GSL. Moreover, activities of cold air mass during early spring are active, and there can sometimes be a sharp decrease of temperature during early spring. Therefore, air temperature during the GSL in general can be greatly modified due to the active activities of cold air mass. GSL is subject to a larger variability due to the largest standard deviation. Besides, the decreasing standard deviation of GSL, GTavg, GTmax, and GTmin can be found from the southeastern to the northwestern Huai River Basin (Figure 9b-e). Meanwhile, a decreasing tendency of DTR could be found landwards (Figure 9a).

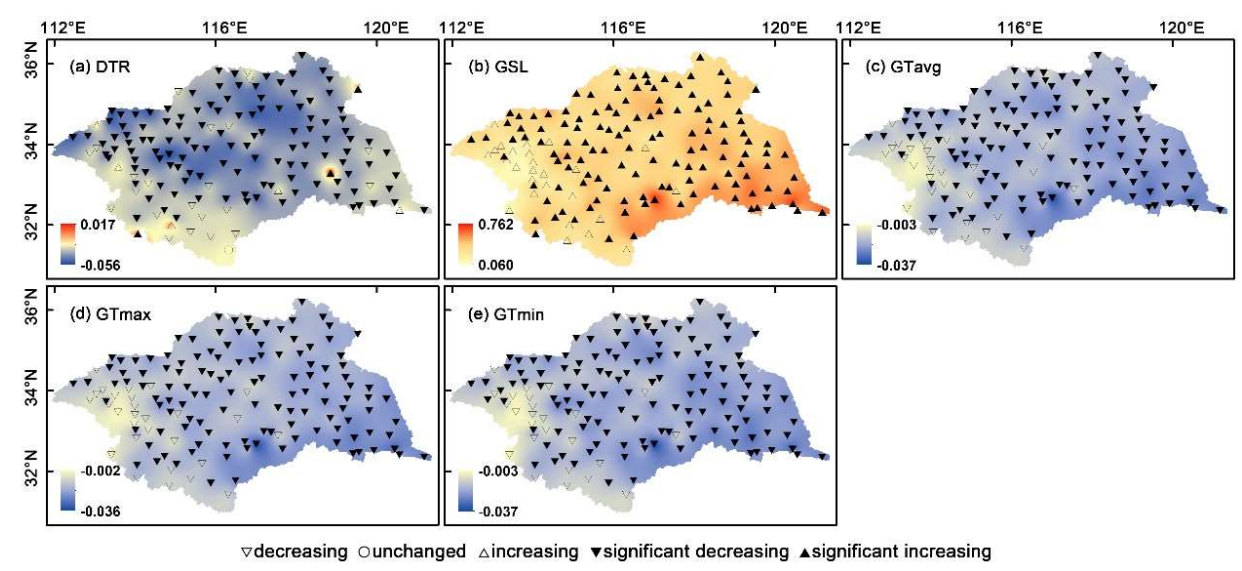

Figure 8. Spatiotemporal patterns of trends in other indices during 1961-2014 across the Huai River Basin.
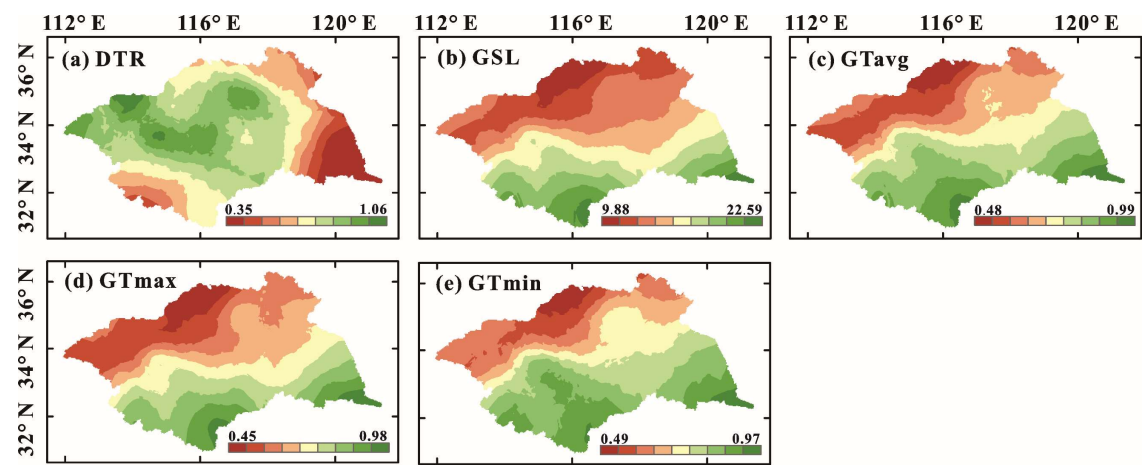

Figure 9. Spatiotemporal patterns of standard deviation in other indices during 1961-2014 across the Huai River Basin. 


\subsection{Abrupt Changes and Correlations of Extreme Temperature Indices}

Abrupt changes of extreme temperature indices are shown in Figure 10. In general, the 1990s was the major change point for extreme temperature indices, such as the extreme maximum temperature indices (e.g., TN90p, SU25, TR20, TN10p), extreme minimum temperature indices (i.e., CWDI), and other indices (e.g., GSL, GTavg, GTmax and GTmin). Meanwhile, the 1980s was another change point for extreme temperature indices such as the extreme maximum temperature indices (TNn), extreme minimum temperature indices (FD0, ID0, CSDI, CFD), and other indices (DTR). As indicated above, change points of the extreme minimum temperature indices were mainly occured in the 1980s, which were earlier than the change points of the extreme maximum temperature indices. Enhanced fluctuations of El Niño/La Nina events were detected after the 1980s; this was particularly true after the 1990s. Climate changes further intensified due to enhanced ENSO (El Niño-Southern Oscillation) regimes and warming processes at the global scale $[21,45,46]$. Therefore, the timing of the change points for the extreme temperature indices, i.e., 1980s and 1990s, can be attributed to ENSO-induced impacts. However, some extreme temperature series were subject to more than one change point, such as HWDI, CSU25, TX10p, and CID. These four extreme temperature index series have four, or even more, change points. These results indicated more than one driving factor behind the extreme temperature indices, such as HWDI, CSU25, TX10p, and CID.

To explore the potential impacts of some extreme temperature indices on others, correlations amongst extreme temperature indices were quantified in this study across the Huai River Basin (Figure 11). It can be seen from Figure 11 that there were no significant correlations between the extreme maximum temperature indices and the extreme minimum temperature indices. Meanwhile, TXx had a significant correlation with $\mathrm{TNx}$, with a correlation coefficient of 0.60 . TXn had a significant correlation with TNn, with a correlation coefficient of 0.79 . Meanwhile, SU35 and CSU35 had a higher correlation, with a correlation coefficient of 0.92 . Besides, better correlation relations could also be found between SU35 and WSDI, SU25 and HWDI, WSDI and CSU35, and TXx and CSU35, with correlation coefficients $0.89,0.88,0.87,0.80$, respectively; these were significant at 0.01 significance level. As for correlations between minimum temperature components, a better correlation could be observed between FD0 and the other cold temperature indices, which were significant at 0.01 significance level. In addition, a significant correlation coefficient could also be obtained between ID0 and CID, which was significant at 0.95 confidence level.

Comparisons between correlation relations amongst temperature indices did not show good correlation between TXn and maximum temperature indices. Meanwhile, better correlation could be found between TXn and the other minimum temperature indices; this was particularly the case for correlation between TXn and CID, ID0, and TNn with correlation coefficients of $-0.82,-0.80$, and 0.79 , respectively. The correlation coefficient between TXX and SU35 was 0.86 , implying that the highest temperature components of the extreme maximum temperature indices series can drive the lengthening of heat waves. In general, a negative correlation could be found between the extreme maximum temperature indices and the extreme minimum temperature indices. A positive correlation could be found among the extreme minimum temperature components. Correlations were better among the extreme minimum temperature components when compared with those among the extreme maximum temperature components, indicating a significant increasing tendency of extreme minimum temperature compared to the moderate changes of the extreme maximum temperature. In particular, the highest correlation coefficient could be found between the GSL (other indices) and FD0 (extreme minimum temperature temperature), showing that a significant decreasing number of freezing days can help lengthen the GSL. 
4 (a) TXX
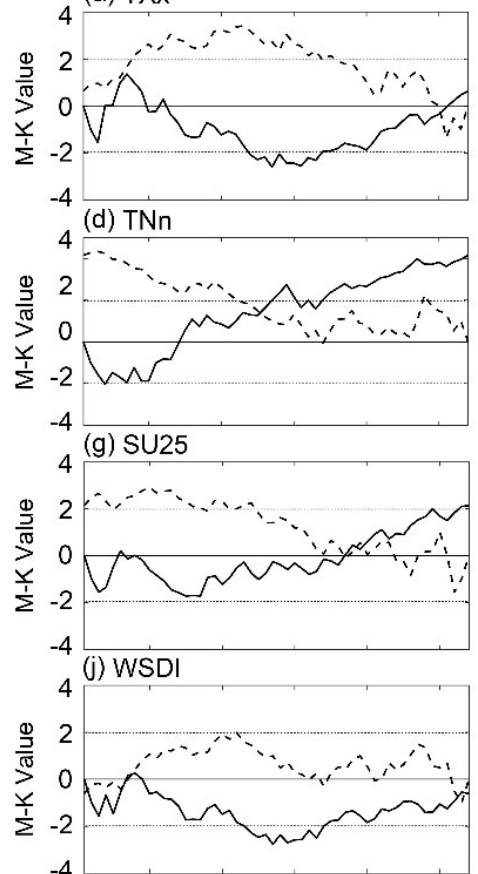

4 (m) CSU35
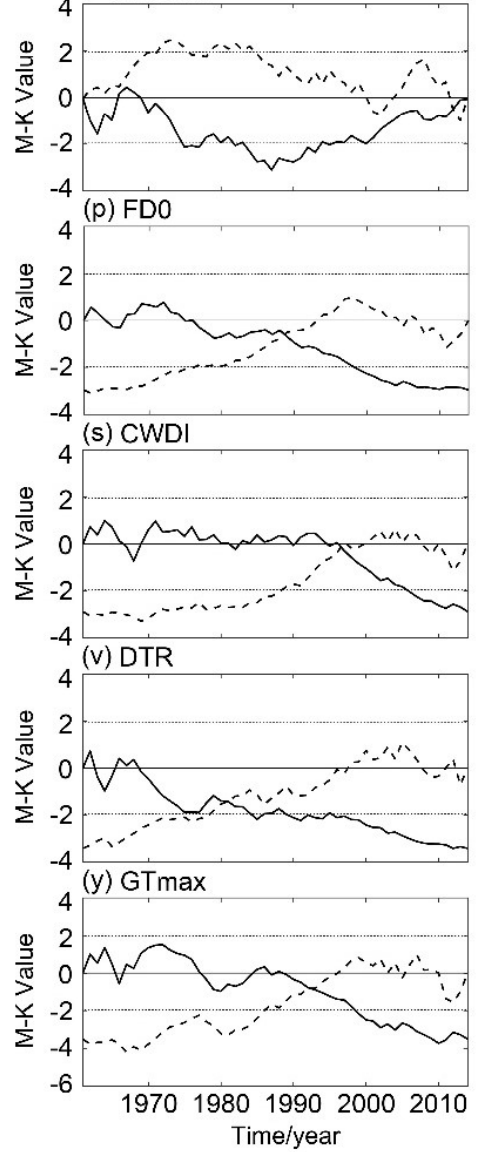

(b) TXn

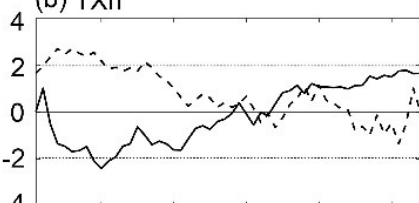

$-4$

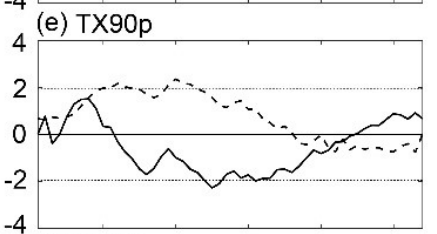

-4 (h) SU35

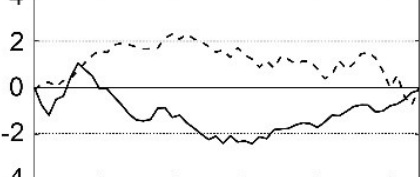

-4 (k) HWDI
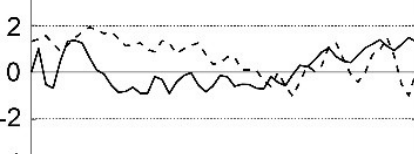

$-4 \frac{1}{\text { (n) TX10p }}$
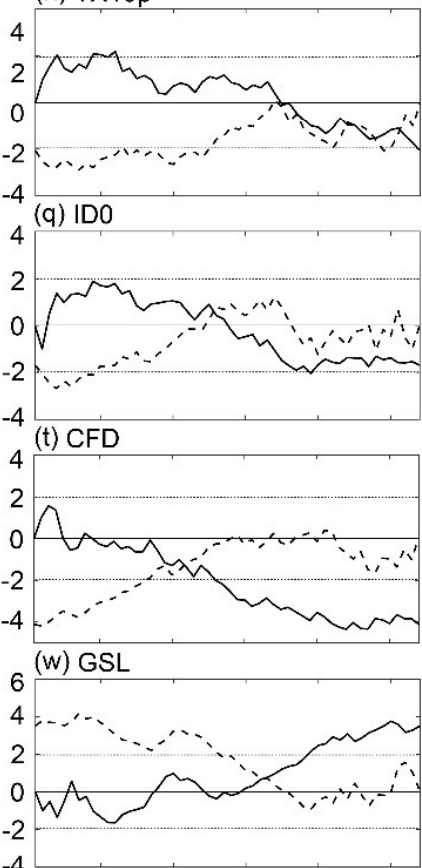

-4 (z) GTmin

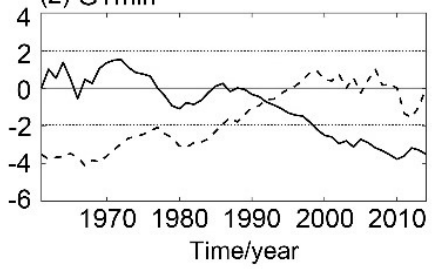

(c) $\mathrm{TNx}$

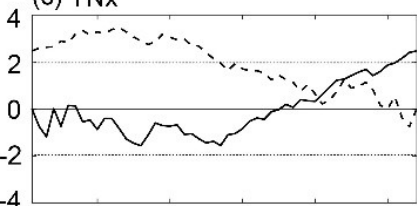

(f) TN90p

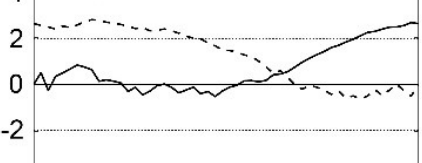

-4 (i) TR20
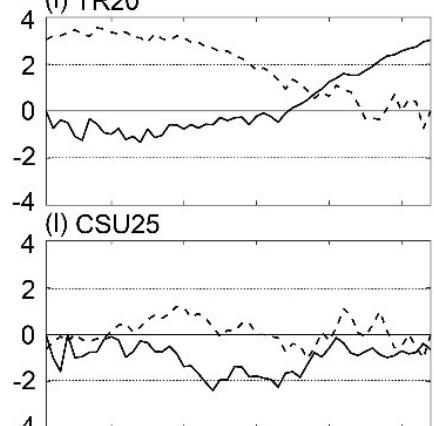

(o) TN10p

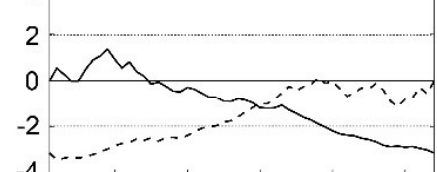

-4 (r) CSDI

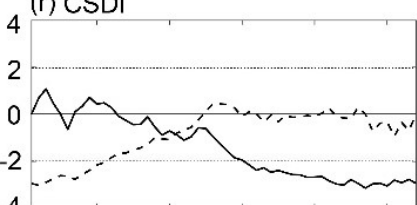

-4 (u) CID

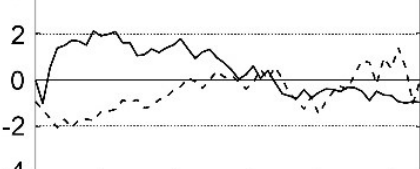

$-4$

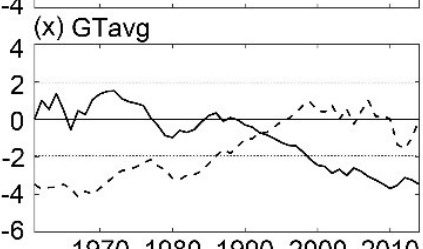

19701980199020002010 Time/year

$\longrightarrow$ UF - - - UB

Figure 10. Abrupt behaviors of extreme temperature indices during 1961-2014 across the Huai River Basin. 


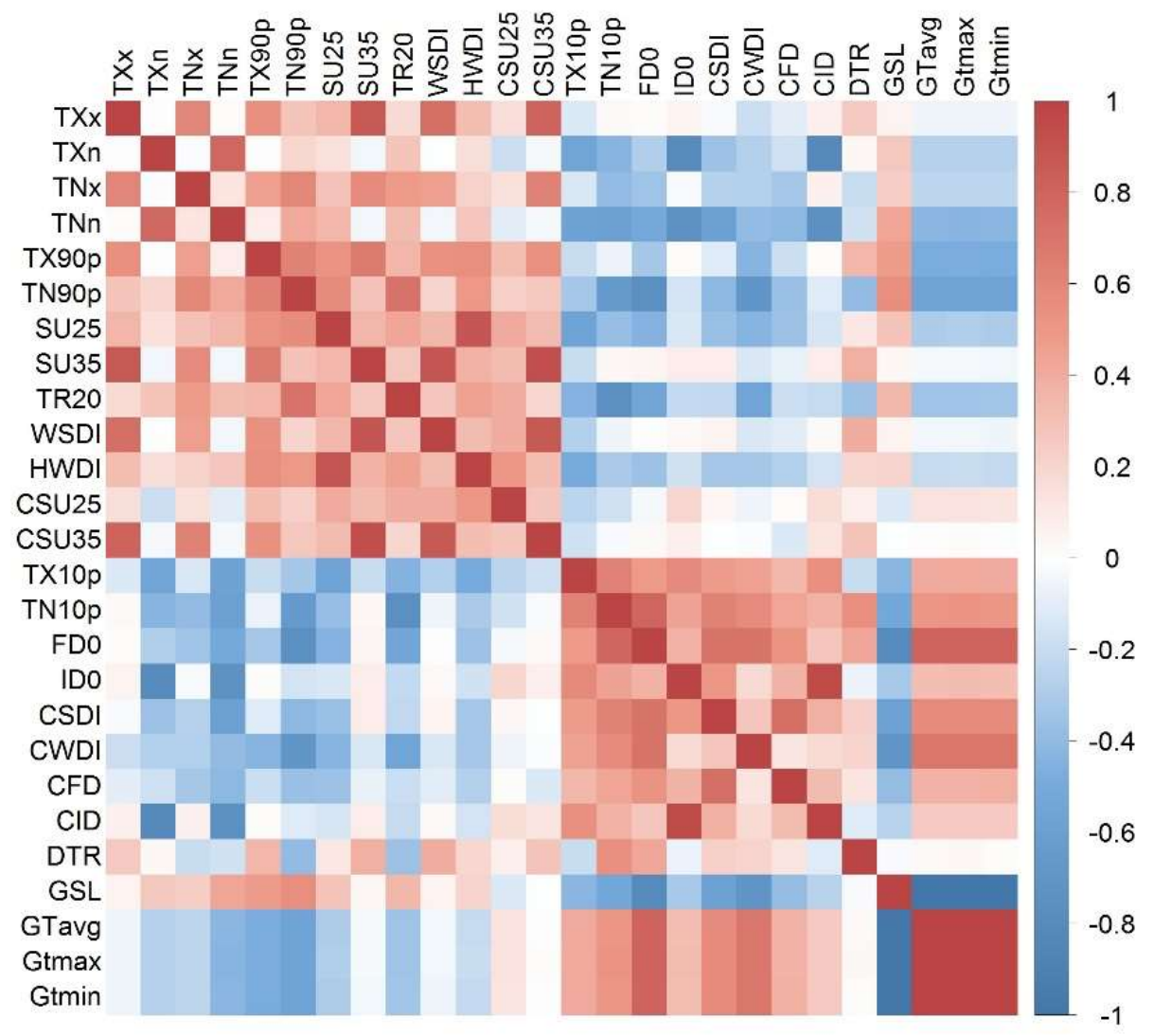

Figure 11. Correlations between extreme temperature indices during 1961-2014 across the Huai River Basin.

\section{Discussion}

\subsection{Relations between Extreme Temperature Indices and Locations (Latitude and Longitude), Altitude}

Correlations between extreme temperature indices, the locations of meteorological stations, and altitude can be found in Table 3. It can be observed from Table 3 that the most extreme temperature indices were in significant correlation with the altitude, latitude, and longitude. A higher correlation could be found between the extreme minimum temperature indices (FD0, CFD) and latitude, with correlation coefficients of 0.92 and 0.91 , respectively, which were significant at 0.01 significance level. Moreover, correlations tended to be enhanced with increasing higher latitude, i.e., there were more freezing days in the northern Huai River Basin than in the southern Huai River Basin. The extreme maximum temperature indices had negative relations with latitude, such as the extreme maximum temperature indices (TR20 and WSDI), which had correlation coefficients of -0.74 and -0.72 . Meanwhile, the other indices (GSL) had a negative correlation with latitude, i.e., the lengthening GSL could be detected in the southern Huai River Basin, and vice versa for the northern Huai River Basin. Altitude had certain impacts on the extreme temperature indices, since ID0 and CID can inflict damages on crops, and hence cause a potential reduction in agricultural production. The higher the altitude, the higher the probability of extreme minimum temperature indices (ID0 and CID), which has a negative impact on agricultural activities and planting policies. Therefore, latitude and altitude have remarkable impacts on extreme temperature indices. 
Table 3. Correlations between extreme temperature indices and latitude, longitude, and altitude across the Huai River Basin.

\begin{tabular}{|c|c|c|c|c|c|c|c|c|c|}
\hline Categories & $\begin{array}{c}\text { Extreme } \\
\text { Temperature } \\
\text { Indices }\end{array}$ & Lat. & Lon. & Alt. & Categories & $\begin{array}{c}\text { Extreme } \\
\text { Temperature } \\
\text { Indices }\end{array}$ & Lat. & Lon. & Alt. \\
\hline \multirow{4}{*}{$\begin{array}{l}\text { Extreme } \\
\text { indices }\end{array}$} & TXX & $0.27 * *$ & $-0.64^{* *}$ & -0.13 & \multirow{6}{*}{$\begin{array}{c}\text { Extreme } \\
\text { minimum } \\
\text { temperature } \\
\text { indices }\end{array}$} & TX10p & $-0.37^{* *}$ & $-0.51 * *$ & $0.18 *$ \\
\hline & $\mathrm{TXn}$ & -0.13 & $0.31^{* *}$ & $-0.64^{* *}$ & & TN10p & -0.09 & 0.15 & 0.04 \\
\hline & $\mathrm{TNx}$ & $-0.41 * *$ & $0.18 *$ & $-0.42^{* *}$ & & FD0 & $0.92 * *$ & -0.12 & $0.29^{* *}$ \\
\hline & $\mathrm{TNn}$ & $-0.21 *$ & 0.01 & 0.03 & & ID0 & $0.44^{* *}$ & $-0.18^{*}$ & $0.87^{* *}$ \\
\hline \multirow{5}{*}{$\begin{array}{c}\text { Extreme } \\
\text { maximum } \\
\text { temperature } \\
\text { indices }\end{array}$} & SU25 & -0.09 & $-0.34^{* *}$ & $-0.64^{* *}$ & & CFD & $0.91 * *$ & $-0.24^{* *}$ & $0.31^{* *}$ \\
\hline & SU35 & $-0.28^{* *}$ & $-0.73^{* *}$ & -0.14 & & CID & $0.50^{* *}$ & $-0.29 * *$ & $0.83^{* *}$ \\
\hline & TR20 & $-0.74^{* *}$ & 0.20 * & $-0.58^{* *}$ & \multirow[b]{3}{*}{ Other indices } & DTR & $0.58^{* *}$ & $-0.49^{* *}$ & -0.09 \\
\hline & WSDI & $-0.72 * *$ & $0.50^{* *}$ & $-0.35^{* *}$ & & GSL & $-0.92 * *$ & -0.02 & $-0.32^{* *}$ \\
\hline & HWDI & $0.88^{* *}$ & 0.02 & -0.05 & & GTavg & 0.10 & $-0.36^{* *}$ & $-0.61^{* *}$ \\
\hline
\end{tabular}

\subsection{Regional Responses of Warming Processes in Huai River Basin to Global Changes}

Comparisons of changes in extreme temperature indices between China and other places in the world find similar changing patterns of extreme temperature indices across both space and time. In general, the highest temperature, the lowest temperature, and the frequency of hot days are increasing. Meanwhile, a decreasing tendency can be found for extreme minimum temperature events. The results of this current study indicated a widespread increase in extreme minimum temperature indices, as well as extreme maximum temperature indices. Extreme minimum temperature events showed significant decreasing trends. No significant trends could be obtained for extreme temperature indices in the Pearl River Basin and in the Xinjiang, which are both in northwestern China, implying that no evident trends of extreme temperature indices could be observed in some specific regions across China. In addition, no evident trends could be detected for TXx (extreme indices) and WSDI (extreme minimum temperature indices), and different trends could be observed for TXx in the eastern and western Huai River Basin. The results of extreme temperature regimes that Alexander (2016) showed indicated similar changing properties of extreme temperature events over the globe and across China [9].

As extreme temperature indices occurred more frequently, their causes have been widely discussed. Global warming has been accepted as the major background behind the higher frequency of extreme maximum temperature events. A comparison of extreme temperature changes between regions across China and around the globe indicated increasing tendencies of extreme temperature events. In particular, elevating trends in extreme maximum temperature indices regimes and decreasing trends in extreme minimum temperature indices regimes were found, implying a decreasing frequency of cold/freezing events and an increasing frequency of warm/heat wave events across the globe (Table 4). Su et al. (2016) reviewed the literature concerning global warming, which indicated a hiatus in global warming [47]. Meanwhile, the frequent occurrence of extreme temperature events is increasing. It can be assumed that long-term (40-60 years) and shorter periods (annual and inter-annual fluctuations) of temperature fluctuations had experienced a warming trend. In general, two causes can be considered for a warming climate, i.e., natural fluctuations and manmade emissions of greenhouse gas [48]. Yan et al. (2017) thoroughly investigated vegetation growth responses towards precipitation patterns in the Huang-Huai-Hai River Basin. Regions with sparse vegetation were mainly distributed in arid and semi-arid areas or densely populated areas [49]. What's more, Chen et al. (2016) found that the highest vulnerability grade at the scale of the Province-Class II WRR (Water Resources Region) was in the lower reaches of the Huai River Basin, in the Jiangsu province [50]. In this study, extreme minimum temperature indices showed a significant increasing trend. Therefore, 
the increasing trend of extreme temperature indices caused a generally increasing trend in reference evapotranspiration in the lower Huai River Basin [34]. Besides, warming effects of urbanization can also be identified in the southeastern Huai River Basin. Moreover, the fifth IPCC (Intergovernmental Panel of Climate Change) reports, which were based on modeling results by the CMIP5 (Coupled Model Intercomparison Project Phase 5), corroborated human contributions through greenhouse gas emissions to the higher frequency of hot days and heat nights, and the lower frequency of cold days and freezing night as well, and hence the widespread increase of heat waves across the continent of the globe.

Table 4. Comparisons of extreme temperature indices across the Huai River Basin and other regions of the globe.

\begin{tabular}{|c|c|c|c|c|c|c|c|c|c|c|c|c|c|c|}
\hline \multirow{2}{*}{ Categories } & \multirow{2}{*}{$\begin{array}{c}\text { Extreme } \\
\text { Temperature } \\
\text { Indices }\end{array}$} & \multicolumn{7}{|c|}{ China } & \multicolumn{6}{|c|}{ Other Countries } \\
\hline & & HR & YR & QL & PR & YLR & $\mathrm{XJ}$ & MC & MG & SB & IT & KY & US & GL \\
\hline \multirow{4}{*}{ Extreme indices } & $\mathrm{TXX}$ & 0 & $\nearrow$ & 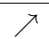 & $\nearrow$ & $\nearrow$ & 0 & $\nearrow$ & & $\nearrow$ & - & - & $\nearrow$ & \\
\hline & TXn & $\nearrow$ & & & 0 & $\nearrow$ & 0 & & & & - & - & $\nearrow$ & \\
\hline & TNx & $\nearrow$ & & & $\nearrow$ & $\nearrow$ & 0 & $\nearrow$ & & & - & - & $\nearrow$ & \\
\hline & $\mathrm{TNn}$ & $\nearrow$ & & & $\nearrow$ & & 0 & 7 & & & - & $\nearrow$ & 7 & \\
\hline \multirow{5}{*}{$\begin{array}{l}\text { Extreme maximum } \\
\text { temperature indices }\end{array}$} & TX90p & 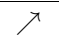 & & & $\nearrow$ & $\nearrow$ & $\pi$ & $\nearrow$ & & $\nearrow$ & $\nearrow$ & $\nearrow$ & $\nearrow$ & \\
\hline & TN90p & & & & & & & & & & $\nearrow$ & $\nearrow$ & & \\
\hline & SU25 & 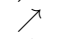 & & & $\nearrow$ & - & $\nearrow$ & J & & & $\nearrow$ & $\nearrow$ & 7 & \\
\hline & TR20 & $\nearrow$ & & & $\nearrow$ & - & $\nearrow$ & $\nearrow$ & & & $\nearrow$ & - & $\nearrow$ & \\
\hline & WSDI & 0 & & & $\nearrow$ & $\nearrow$ & $\nearrow$ & & - & & $\nearrow$ & $\nearrow$ & - & \\
\hline \multirow{5}{*}{$\begin{array}{l}\text { Extreme minimum } \\
\text { temperature indices }\end{array}$} & TX10p & 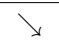 & & & 0 & & & & & & $\searrow$ & $\nearrow$ & $y$ & \\
\hline & TN10p & $y^{\prime}$ & & & $\searrow$ & & & & & & $\searrow$ & $\nearrow$ & 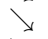 & \\
\hline & FD0 & $\searrow$ & & & $\searrow$ & $\searrow$ & $\searrow$ & & & & $\searrow$ & - & $\searrow$ & \\
\hline & ID0 & 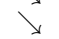 & & & $0^{-1}$ & $\searrow$ & $\searrow$ & & & & $\searrow$ & - & $\searrow$ & \\
\hline & CSDI & - & & $\searrow$ & $\searrow$ & - & $\searrow$ & 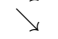 & - & $\searrow$ & $\searrow$ & - & - & $\searrow$ \\
\hline \multirow{2}{*}{ Other indices } & DTR & $y$ & $\searrow$ & $\searrow$ & $\searrow$ & $\searrow$ & 0 & - & $\searrow$ & $\nearrow$ & - & $\searrow$ & - & ע \\
\hline & GSL & $\pi$ & $\nearrow$ & $\nearrow$ & 0 & $\pi$ & $\nearrow$ & - & $\nearrow$ & 7 & $\nearrow$ & - & - & \\
\hline
\end{tabular}

Note: HR: Huai River Basin; YR: Yangtze River Basin; QL: Qinling Mountains; PR: Pearl River Basin; YLR: Yellow River Basin; XJ: Xinjiang; MC: Mainland China; MG: Mongolia; SB: Serbia; IT: Italy; KY: Kenya; US: United States; GL: globe. $\nearrow$ denotes increasing temperature indices; \denotes decreasing temperature indices; $\bigcirc$ denotes no significant trends in temperature indices; and — denotes no data.

\section{Conclusions}

Global warming and its negative impacts on the ecological environment and human society have drawing increasing human concerns. However, current standing reports that focus on the changing properties of temperature extremes have used a limited number of temperature indices at the regional and even global scales. Besides, most of the researches have mainly pertained to specific temperature indices, such as heat waves. Against the above-mentioned research studies, this current study aims to thoroughly investigate the spatiotemporal patterns of extreme temperature indices based on widely accepted temperature indices. Moreover, this study also considered the relationships between temperature indices, as well as those between temperatures indices and the length of the growing season. At the same time, the regional responses of extreme temperature indices to global warming across the Huai River Basin have also been dissected.

The aforementioned points differentiate this current research from standing research studies. The above-mentioned analyses that were done in this study can help to obtain the following important and interesting conclusions:

(1) Extreme indices (TXx, TNx, TXn, and TNn) have shown generally increasing tendencies, while a widespread increase could also be detected in TNx and TNn, with the largest increasing magnitudes of $0.4{ }^{\circ} \mathrm{C}$ per decade and $1.3{ }^{\circ} \mathrm{C}$ per decade, respectively. The minimum air temperature regimes have had a larger increasing magnitude than the maximum air temperature.

(2) The extreme maximum temperature indices showed increasing trends, and the significantly increasing trends in TN90p and TR20 were greater in magnitude than those related to the other extreme maximum temperature indices. Meanwhile, the extreme minimum temperature indices 
showed significant decreasing trends. The increasing trends of the extreme maximum temperature indices, and the decreasing trend of the extreme minimum temperature indices caused the GSL to increase. Although an increasing GSL is beneficial for increasing the growth time of crops, the decreasing extreme minimum temperature and increasing extreme maximum temperature may reduce the winter wheat yield. The remarkable increase in the minimum temperature and decrease of cold days, and hence the lengthening of the growing season, may imply shifting agricultural activities in terms of plant timing and crop types.

(3) The magnitude of trends regarding extreme minimum temperatures was larger than that regarding extreme maximum temperatures. The changing magnitude of the night-time temperature indices was larger than that of the daytime periods. The changing magnitude and significance of the extreme temperature indices in the eastern Huai River Basin were larger than those of the western Huai River Basin. Meanwhile, the extreme maximum temperature in the southeastern Huai River Basin was larger than that of the other regions of the Huai River Basin. This difference could be attributed to urban heating effects across the Yangtze Delta region, where urban aggregation is dominant. With the exception of CSU25, other extreme maximum temperature indices showed significant increasing trends in most of regions in the southeastern Huai River Basin, which should be attributed to the booming socioeconomic development in the southeastern Huai River Basin. Besides, fast urbanization and related urban heat island effects have also increased the extreme maximum temperature indices components. In addition, correlations amongst the extreme minimum temperatures were relatively higher than those amongst the extreme maximum temperature indices. Most of the extreme temperature indices showed close relationships to altitude and latitude. Latitude had the largest impacts on the extreme temperature, followed by altitude. Specifically, the GSL showed negative relations with altitude, and negative correlations could also be detected between longitude and the extreme minimum temperature. There were less days with extreme minimum temperatures in the eastern Huai River Basin than in the western Huai River Basin, which could be attributed to the higher temperature in the seaward regions than in the landward regions. A decrease in the extreme minimum temperature indices could also be detected in the western Huai River Basin; however, this decrease was not significant. This decrease did not significantly lengthen the GSL, since ID0 and CID both cause damage or death for crops, and thus great damage to agricultural production. The higher the altitude, the higher the probability of extreme minimum temperature indices (ID0 and CID), which have a great impact on agricultural activities and planting policies. Similar changing properties of the extreme temperature indices can be identified over the globe when compared with those across the Huai River Basin, China; these similarities indicate that warming processes in the Huai River Basin are indicative of greater global warming trends.

Acknowledgments: This work is financially supported by National Natural Science Foundation of China (Grant No.: 41601023; 51409002), the National Science Foundation for Distinguished Young Scholars of China (Grant No.: 51425903), Fund for Creative Research Groups of National Natural Science Foundation of China (Grant No.: 41621061), Project Supported by State Key Laboratory of Earth Surface Processes and Resource Ecology (Grant No.: 2017-KF-04), Natural Science Foundation of Anhui province (Grant No.: 1808085QD117), Open Research Fund of State Key Laboratory of Simulation and Regulation of Water Cycle in River Basin (China Institute of Water Resources and Hydropower Research) (Grant No. IWHR-SKL-201720) and the Research Grants Council of the Hong Kong Special Administrative Region, China (Grant No.: HKBU 22301916). Our gratitude should be extended to the editor of Water and anonymous reviewers for their professional and pertinent comments and suggestions which are greatly helpful for further quality improvement of this manuscript.

Author Contributions: For research articles with several authors, a short paragraph specifying their individual contributions must be provided. The following statements should be used "Peng sun, Qiang Zhang and Changqing Song. conceived and designed the experiments; Peng sun, Qiang Zhang, Rui Yao, Vijay P Singh and Changqing Song. performed the experiments; Peng sun, Qiang Zhang and Changqing Song analyzed the data; Peng sun, Qiang Zhang, Rui Yao, Vijay P Singh and Changqing Song contributed reagents/materials/analysis tools; Peng sun, Qiang Zhang, Rui Yao, Vijay P Singh and Changqing Song wrote the paper." Authorship must be limited to those who have contributed substantially to the work reported.

Conflicts of Interest: The authors declare no conflict of interest. 


\section{References}

1. Fearnside, M.P. Forests and global warming mitigation in Brazil: Opportunities in the Brazilian forest sector for responses to global warming under the "clean development mechanism". Biomass Bioenergy 1999, 16, 171-189. [CrossRef]

2. Cox, P.M.; Betts, R.A.; Jones, C.D.; Spall, S.A.; Totterdell, I.J. Acceleration of global warming due to carbon-cycle feedbacks in a coupled climate model. Nature 2008, 408, 184-187. [CrossRef] [PubMed]

3. Kurane, I. The effect of global warming on infectious diseases. Publ. Health Res Perspect. 2000, 1, 4-9. [CrossRef] [PubMed]

4. Zhang, Q.; Li, J.; Singh, V.P.; Xiao, M.Z. Spatio-temporal relations between temperature and precipitation regimes: Implications for temperature-induced changes in the hydrological cycle. Glob. Planet. Chang. 2013, 111, 57-76. [CrossRef]

5. Sterl, A.; Severijins, C.; Dijkstra, H.; Hazeleger, W.; Oldenborgh, G.J.; Broeke, M.V.; Burgers, G. When can we expect extremely high surface temperature? Geophys. Res Lett. 2008, 35, L14703. [CrossRef]

6. Min, E.; Hazelege, W.; Oldenborgh, G.J.; Sterl, A. Evaluation of trends in high temperature extremes in north-western Europe in regional climate models. Environ. Res. Lett. 2013, 8, 014011. [CrossRef]

7. Easterling, D.; Meehl, G.A.; Parmeasn, C.; Changnon, S.A.; Karl, T.R.; Mearns, L.O. Climate extremes: Observations, modeling, and impacts. Science 2000, 289. [CrossRef]

8. Vincent, L.A.; Peterson, T.C.; Barros, V.R.; Marino, M.B.; Rusticucci, M.; Carrasco, G.; Ramirez, E.; Alves, L.M.; Ambrizzi, T.; Berlato, M.A.; et al. Observed trends in indices of daily temperature extremes in South America 1960-2000. J. Clim. 2005, 18, 5011-5023. [CrossRef]

9. Alexander, L.V.; Zhang, X.; Peterson, T.C.; Caesar, J.; Gleason, B.; Klein Tank, A.M.; Haylock, M.; Collins, D.; Trewin, B.; Rahimzadeh, F.; et al. Global observed changes in daily climate extremes of temperature and precipitation. J. Geophys. Res. 2006, 111, D05109. [CrossRef]

10. Lau, N.-C.; Nath, M.J. A model study of heat waves over North America: Meteorological aspects and projections for the twentyfirst century. J. Clim. 2012, 25, 4761-4784. [CrossRef]

11. Chen, Y.D.; Li, J.; Zhang, Q. Changes in site-scale temperature extremes over China during 2071-2100 in CMIP5 simulations. J. Geophys. Res. Atmos. 2016, 121, 2732-2749. [CrossRef]

12. Zhang, Q.; Li, J.; Chen, Y.D.; Chen, X. Observed changes of temperature extremes during 1960-2005 in China: Natural or human-induced variations? Theor. Appl. Climatol. 2011, 106, 417-431. [CrossRef]

13. Hansen, J.; Sato, M.; Ruedy, R.; Lo, K.; Lea, D.W.; Medina-Elizade, M. Global temperature change. Proc. Natl. Acad. Sci. USA 2006, 103, 14288-14293. [CrossRef] [PubMed]

14. Mann, M.E.; Gille, E.; Bradley, R.S.; Hughes, M.K.; Overpeck, J.; Keimig, F.T.; Gross, W. Global temperature patterns in past centuries: An interactive presentation. Earth Interact. 2000, 4, 1-29. [CrossRef]

15. Cao, L.J.; Zhao, P.; Yan, Z.; Jones, P.; Zhu, Y.; Yu, Y.; Tang, G. Instrumental temperature series in eastern and central China back to the nineteenth century. J. Geophys. Res. Atmos. 2013, 118, 8197-8207. [CrossRef]

16. Christidis, N.; Stott, P.A.; Brown, S.; Hegerl, G.C.; Caesar, J. Detection of changes in temperature extremes during the second half of the 20th century. Geophys. Res. Lett. 2005, 32, 242-257. [CrossRef]

17. Christidis, N.; Stott, P.A. Attribution analyses of temperature extremes using a set of 16 indices. Weather Clim. Extremes 2016, 14, 24-35. [CrossRef]

18. Dashkhuu, D.; Kim, J.P.; Chun, J.A.; Lee, W.-S. Long-term trends in daily temperature extremes over Mongolia. Weather Clim. Extremes 2015, 8, 26-33. [CrossRef]

19. Ruml, M.; Gregorić, E.; Vujadinović, M.; Radovanović, S.; Matović, G.; Vuković, A.; Počuča, V.; Stojičić, D. Observed changes of temperature extremes in Serbia over the period 1961-2010. Atmos. Res. 2017, 183, $26-41$. [CrossRef]

20. Lin-Ye, J.; García-León, M.; Gràcia, V.; Ortego, M.I.; Stanica, A.; Sánchez-Arcilla, A. Multivariate Hybrid Modelling of Future Wave-Storms at the Northwestern Black Sea. Water 2018, 10, 221. [CrossRef]

21. Zhang, Q.; Zheng, Y.; Singh, V.P.; Luo, M.; Xie, Z. Summer extreme precipitation in eastern China: Mechanisms and impacts. J. Geographys. Res. 2017, 122, 2766-2778. [CrossRef]

22. Zhou, D.; Zhao, S.; Liu, S.; Zhang, L.; Zhu, C. Surface urban heat island in China's 32 major cities: Spatial patterns and drivers. Remote Sens. Environ. 2014, 152, 51-61. [CrossRef] 
23. Zhou, D.; Zhao, S.; Zhang, L.; Sun, G.; Liu, Y. The footprint of urban heat island effect in China. Sci. Rep. 2015, 5, 11160. [CrossRef] [PubMed]

24. Zhang, Q.; Sun, P.; Singh, V.P.; Chen, X. Spatial-temporal precipitation changes (1956-2000) and their implications for agriculture in China. Glob. Planet. Chang. 2012, 82-83, 86-95. [CrossRef]

25. Sun, P.; Zhang, Q.; Wen, Q.Z.; Singh, V.P.; Shi, P.J. Multisource data based integrated agricultural drought monitoring in the Huai River basin, China. J. Geophys. Res. 2017. [CrossRef]

26. Fang, S.; Jia, R.; Tu, W.; Sun, Z. Assessing Factors Driving the Change of Irrigation Water-Use Efficiency in China Based on Geographical Feature. Water 2017, 9, 759. [CrossRef]

27. Zhu, Y.; Wang, H.; Zhou, W.; Ma, J. Recent changes in the summer precipitation pattern in Eastern China and the background circulation. Clim. Dyn. 2011, 36, 1463-1473. [CrossRef]

28. The Huaihe River Commission of the Ministry of Water Resources, P.R.C. Introduction: Huaihe River Basin. 2008. Available online: http:/ / www.hrc.gov.cn/lyjs.jhtml (accessed on 11 March 2018).

29. Sun, P.; Sun, Y.Y.; Zhang, Q.; Shi, P.J.; Wen, Q.Z. Temporal and spatial variation characteristic of runoff processes and its cause in Huaihe Basin. J. Lake Sci. 2018, 30, 497-508.

30. Wang, L.; Yuan, X.; Xie, Z.; Wu, P.; Li, Y. Increasing flash droughts over China during the recent global warming hiatus. Sci. Rep. 2016, 6, 30571. [CrossRef] [PubMed]

31. Ci, H.; Zhang, Q.; Singh, V.P.; Xiao, M.; Liu, L. Spatiotemporal properties of growing season indices during 1961-2010 and possible association with agroclimatological regionalization of dominant crops in Xinjiang, China. Meteorol. Atmos. Phys. 2016, 128, 513-524. [CrossRef]

32. Xiao, M.Z.; Zhang, Q.; Singh, V.P.; Chen, X.H. Probabilistic forecasting of seasonal drought behaviors in the Huai River basin, China. Theor. Appl. Climatol. 2017, 128, 667-677. [CrossRef]

33. Zhou, T.; Wang, F.; Yang, Z. Comparative Analysis of ANN and SVM Models Combined with Wavelet Preprocess for Groundwater Depth Prediction. Water 2017, 9, 781. [CrossRef]

34. Li, M.; Chu, R.; Shen, S.; Islam, A.R.M.T. Quantifying Climatic Impact on Reference Evapotranspiration Trends in the Huai River Basin of Eastern China. Water 2018, 10, 144. [CrossRef]

35. Ma, F.; Yuan, X.; Ye, A. Seasonal drought predictability and forecast skill over China. J. Geophys. Res. 2015, 120, 8264-8275. [CrossRef]

36. Zhang, Q.; Singh, V.P.; Li, J.; Chen, X. Analysis of the periods of maximum consecutive wet days in China. J. Geophys. Res. 2011, 116, D23106. [CrossRef]

37. Sen, P.K. Estimates of the regression coefficient based on Kendall's tau. J. Am. Stat. Assoc. 1968, 63, 1379-1389. [CrossRef]

38. Gocic, M.; Trajkovic, S. Analysis of changes in meteorological variables using Mann-Kendall and Sen's slope estimator statistical tests in Serbia. Glob. Planet. 2013, 100, 172-182. [CrossRef]

39. Kahya, E.; Kalayc, I.S. Trend analysis of streamflow in Turkey. J. Hydrol. 2004, 289, 128-144. [CrossRef]

40. Gerstengarbe, F.W.; Werner, P.C. Estimation of the beginning and end of recurrent events within a climate regime. Clim. Res. 1999, 11, 97-107. [CrossRef]

41. Zhang, Q.; Sun, P.; Jiang, T.; Tu, X.; Chen, X. Spatio-temporal patterns of hydrological processes and their responses to human activities in the Poyang Lake basin, China. Hydrol. Sci. J. 2011, 56, 305-318. [CrossRef]

42. Karl, T.R.; Janes, P.D.; Knight, R.W.; Kukla, J.; Plummer, N.; Razuvayev, V.; Gallo, K.P.; Lindesay, J.; Charlson, R.J.; Peterson, T.C. A symmetric trends of daily maximum and minimum temperatures: Empirical evidence and possible causes. Bull. Am. Math. Soc. 1993, 74, 1007-1023. [CrossRef]

43. Zhang, Q.; Xu, C.-Y.; Zhang, Z.X.; Ren, G.Y. Climate change or variability? The case of Yellow river as indicated by extreme maximum and minimum air temperature during 1960-2004. Theor. Appl. Climatol. 2008, 93, 35-43. [CrossRef]

44. Zhang, G.; Liu, X.; Wang, Y.; Luo, C.; Jiao, G.; Wang, C.; Yang, D. Response of Winter Wheat to Temperature Warming in Northern Regions of Henan Province. Chin. Agric. Sci. Bull. 2011, 27, 234-239.

45. Andrews, E.D.; Antweiler, R.C.; Neiman, P.J.; Ralph, F.M. Influence of ENSO on Flood Frequency along the California Coast. J. Clim. 2004, 17, 337-348. [CrossRef]

46. Ashok, K.; Behera, S.; Rao, A.S.; Weng, H.Y.; Yamagata, T. El Niño Modoki and its possible teleconnection. J. Geophys. Res. 2007, 112, C11007. [CrossRef] 
47. Su, J.; Wen, M.; Ding, Y.; Gao, Y.; Song, Y. Hiatus of Global Warming: A Review. Chin. J. Atmos. Sci. 2016, 40, 1143-1153. [CrossRef]

48. Qin, D. Climate change science and sustainable development. Prog. Geogr. 2014, 33, 874-883.

49. Yan, D.; Xu, T.; Girma, A.; Yuan, Z.; Weng, B.; Qin, T.; Do, P.; Yuan, Y. Regional Correlation between Precipitation and Vegetation in the Huang-Huai-Hai River Basin, China. Water 2017, 9, 557. [CrossRef]

50. Chen, J.; Xia, J.; Zhao, Z.; Hong, S.; Liu, H.; Zhao, F. Using the RESC model and diversity indexes to assess the cross-scale water resource vulnerability and spatial heterogeneity in the Huai River Basin, China. Water 2016, 8, 431. [CrossRef]

(C) 2018 by the authors. Licensee MDPI, Basel, Switzerland. This article is an open access article distributed under the terms and conditions of the Creative Commons Attribution (CC BY) license (http:/ / creativecommons.org/licenses/by/4.0/). 